Article

\title{
Power Quality Improvement with a Pulse Width Modulation Control Method in Modular Multilevel Converters under Varying Nonlinear Loads
}

\author{
Majid Mehrasa ${ }^{1, *}$, Radu Godina $^{2}\left(\mathbb{D}\right.$, Edris Pouresmaeil ${ }^{3}(\mathbb{D})$, Eduardo M. G. Rodrigues ${ }^{4, *(D)}$ and \\ João P. S. Catalão ${ }^{5}$ \\ 1 Department of Engineering and Architecture, The University of Trieste, 34127 Trieste, Italy \\ 2 UNIDEMI, Department of Mechanical and Industrial Engineering, NOVA School of Science and Technology, \\ Universidade NOVA de Lisboa, 2829-516 Caparica, Portugal; r.godina@fct.unl.pt \\ 3 Department of Electrical Engineering and Automation, Aalto University, 02150 Espoo, Finland; \\ edris.pouresmaeil@aalto.fi \\ 4 Management and Production Technologies of Northern Aveiro-ESAN, \\ 3720-509 Oliveira de Azeméis, Portugal \\ 5 Faculty of Engineering of the University of Porto and INESC TEC, 4200-465 Porto, Portugal; catalao@fe.up.pt \\ * Correspondence: m.majidmehrasa@gmail.com (M.M.); emgrodrigues@ua.pt (E.M.G.R.)
}

Received: 3 March 2020; Accepted: 5 May 2020; Published: 9 May 2020

\begin{abstract}
In order to reach better results for pulse width modulation (PWM)-based methods, the reference waveforms known as control laws have to be achieved with good accuracy. In this paper, three control laws are created by considering the harmonic components of modular multilevel converter (MMC) state variables to suppress the circulating currents under nonlinear load variation. The first control law consists of only the harmonic components of the MMC's output currents and voltages. Then, the second-order harmonic of circulating currents is also involved with both upper and lower arm currents in order to attain the second control law. Since circulating current suppression is the main aim of this work, the third control law is formed by measuring all harmonic components of circulating currents which impact on the arm currents as well. By making a comparison between the switching signals generated by the three proposed control laws, it is verified that the second-order harmonic of circulating currents can increase the switching losses. In addition, the existence of all circulating current harmonics causes distributed switching patterns, which is not suitable for the switches' lifetime. Each upper and lower arm has changeable capacitors, named "equivalent submodule (SM) capacitors" in this paper. To further assess these capacitors, eliminating the harmonic components of circulating currents provides fluctuations with smaller magnitudes, as well as a smaller average value for the equivalent capacitors. Moreover, the second-order harmonic has a dominant role that leads to values higher than $3 \mathrm{~F}$ for equivalent capacitors. In comparison with the first and second control laws, the use of the third control-law-based method will result in very small circulating currents, since it is trying to control and eliminate all harmonic components of the circulating currents. This result leads to very small magnitudes for both the upper and lower arm currents, noticeably decreasing the total MMC losses. All simulation results are verified using MATLAB software in the SIMULINK environment.
\end{abstract}

Keywords: modular multilevel converter; control laws; harmonic component; second-order harmonic; circulating currents 


\section{Introduction}

Among the various kinds of multilevel converters [1-3], modular multilevel converters (MMCs) have attracted increasing attention for various industrial applications such as Static Synchronous Compensators (STATCOM) [4], energy storage systems [5], power electronic-based transformers [6], rolling mill factories [7], high-voltage direct current (HVDC) [8-10], solar photovoltaics [11], grid-connected conditions [12], and motor drives [13]; simultaneously, many new modulation-based control strategies have been recently developed in order to present more effective controllers for these kinds of multilevel converters [14]. Several publications have focused on proposing modulation techniques with the aim of reducing capacitor voltage ripples and switching losses, as well as allowing a smaller cell capacitor size for MMCs [15,16]. In [17], a discontinuous modulation-based control strategy was designed for MMCs based on adding a zero sequence to the basic modulation signals. This strategy caused the MMC arms to be clamped with the upper or lower terminals of the dc-link bus, which can help minimize the switching losses and noticeably reduce the capacitor voltage ripples, especially for low modulation indices [17]. Another reduced-switching-frequency-based modulation technique was proposed for MMCs in [18] that can also suppress the circulating currents. On the other hand, in order to reach a smaller cell capacitor size without an increment in the total device rating and decrement in the dc current control capability, a phase-shifted square wave modulation (PS-SWM) strategy was proposed for MMCs in [19]. Moreover, for achieving reduced switching losses with good harmonic performance, a novel modulation method which consists of a combination of fundamental frequency modulation and multi-carrier-based sinusoidal pulse width modulation schemes was presented in [20].

A growing trend towards space vector (SV)-based modulations [21] for the control of MMCs has arisen in recent years. In [22], a dual space vector pulse width modulation strategy was designed for an MMC. Eliminating the arm voltage balancing control, independent controllers for the three-phase upper and lower arms employing redundant switching vectors for capacitor voltage balancing, and reducing the current sensors used by $50 \%$ were the achievements of this strategy [22]. On the other hand, space vector pulse width modulations were applied to MMCs for fault-tolerant challenges [23] and electric ship propulsion systems [24] as well. Optimization issues were involved with control of the space vector modulation-based MMC in [25]. In this referenced work, the maximum level numbers were achieved along with optimized performance of decreasing common-mode voltage, balancing of the capacitor voltage, and elimination of the circulating currents [25].

Optimal pulse width modulation (PWM) has been a popular discussion topic, leading to proposals of new modulation-based control techniques for MMCs in recent years [26]. In [27], synchronous optimal pulse width (SOP) was enhanced for MMCs in order to obtain improved quality of converter output currents, low device switching frequency, and desired values of capacitor voltages. Optimized phase disposition (PD) modulation for MMCs was proposed in [28] with the help of a single PD modulator for the entire upper and lower arms as important parts for the control of MMCs [29]. This single modulator was implemented through a state machine decoder which had the duty of distributing the balanced switching pulses to all submodules [28].

Another optimal pulse width modulation strategy for reducing the common-mode voltage of a medium-voltage modular multilevel converter that fed open-end stator winding induction motor drives was designed in [30]. The achievements of the modulation-based control technique designed in [30] are low switching frequency, minimized harmonic currents of the machine stator, elimination of common-mode voltages of the machine stator windings, and the desired capacitor voltages.

Other modulation strategies have also been considered to improve MMC performance in various operating conditions. In [31], a new function-based modulation control technique for MMCs was designed; it is noticeably less complex when compared to the existing control methods and is proper for the conditions of load and parameter variations. In [32], a new modulation technique based on generalized low-cost computational decoupled sampled average PWM was designed for MMCs in which two averaged nearest voltage levels from the upper and lower arms in each sample period 
were utilized to drive the reference output voltages [32]. This modulation-based control strategy was completed via a simplified voltage balancing method [32]. In addition, two novel modulation strategies were proposed for HVDC and wind farm integration applications in [33] and [34], respectively. A new modulation method, along with a capacitor voltage balancing method, was presented in [35] that was able to provide fixed switching frequency at $50 \mathrm{~Hz}$. Using reference [35], located at the nearest voltage level control, the switching angles were calculated, and then every four pulse patterns were grouped together in order to assess the average of the $\mathrm{dc}$ and fundamental ac components in the output voltages of individual submodules [36,37].

In this paper, three control laws are proposed in order to suppress the circulating currents and provide stable performance for MMCs under nonlinear load variation, since a study regarding linear load was already made in [38]. To design the three proposed control laws, the harmonic components of MMC output voltages, MMC output currents, and circulating currents are utilized. Three novelties are presented that cannot be found in previous works. These novelties are the following: (1) For the first time, an accurate mathematical equation is achieved for an MMC arm capacitor. This equation can be employed for approaching more stable operating conditions for MMCs. (2) In the proposed control strategy, the harmonic components of all MMC state variables are considered to reach full stable operation for the MMC under various operating conditions. (3) A comprehensive assessment related to how the second-order component and other harmonic components of circulating currents can impact the switching signals and equivalent submodule (SM) capacitors is executed. On the other hand, the following contributions are accomplished as well: (1) The proposed control strategies are designed in an $a-b-c$ reference frame, leading to simplicity of performance and highly reducing the calculation burden of the controller design process. (2) Also, it is demonstrated that the appropriate control of circulating current harmonics can significantly reduce the total MMC losses. The paper is organized as follows. The MMC under study is described in Section 2. The proposed control strategies are discussed in Section 3. Evaluation of the proposed control laws is accomplished in Section 4. Section 5 is dedicated to obtaining the equivalent SM capacitors of the MMC's arms. Section 6 presents the simulation results in the MATLAB/SIMULINK environment. Finally, in Section 7, the conclusions are drawn.

\section{The Modular Multilevel Converter (MMC)}

The general structure of the MMC under study in this paper is shown in Figure 1. This MMC consists of $n$-many SMs in series in each arm, in which the SM voltage should be equal to $\mathrm{V}_{\mathrm{dc}} / \mathrm{N}$. Inductance and resistance elements are present in both arms and outbranches of the considered MMC, as depicted in Figure 1. Considering the current directions, the relationship between the upper and lower arm currents and the MMC output current can be stated as (1):

$$
i_{k}=i_{u k}+i_{l k}
$$

On the other side, the MMC circulating currents can be written as follows (2):

$$
i_{c i r k}=\frac{\left(i_{u k}-i_{l k}\right)}{2}-\frac{i_{d c}}{3} .
$$




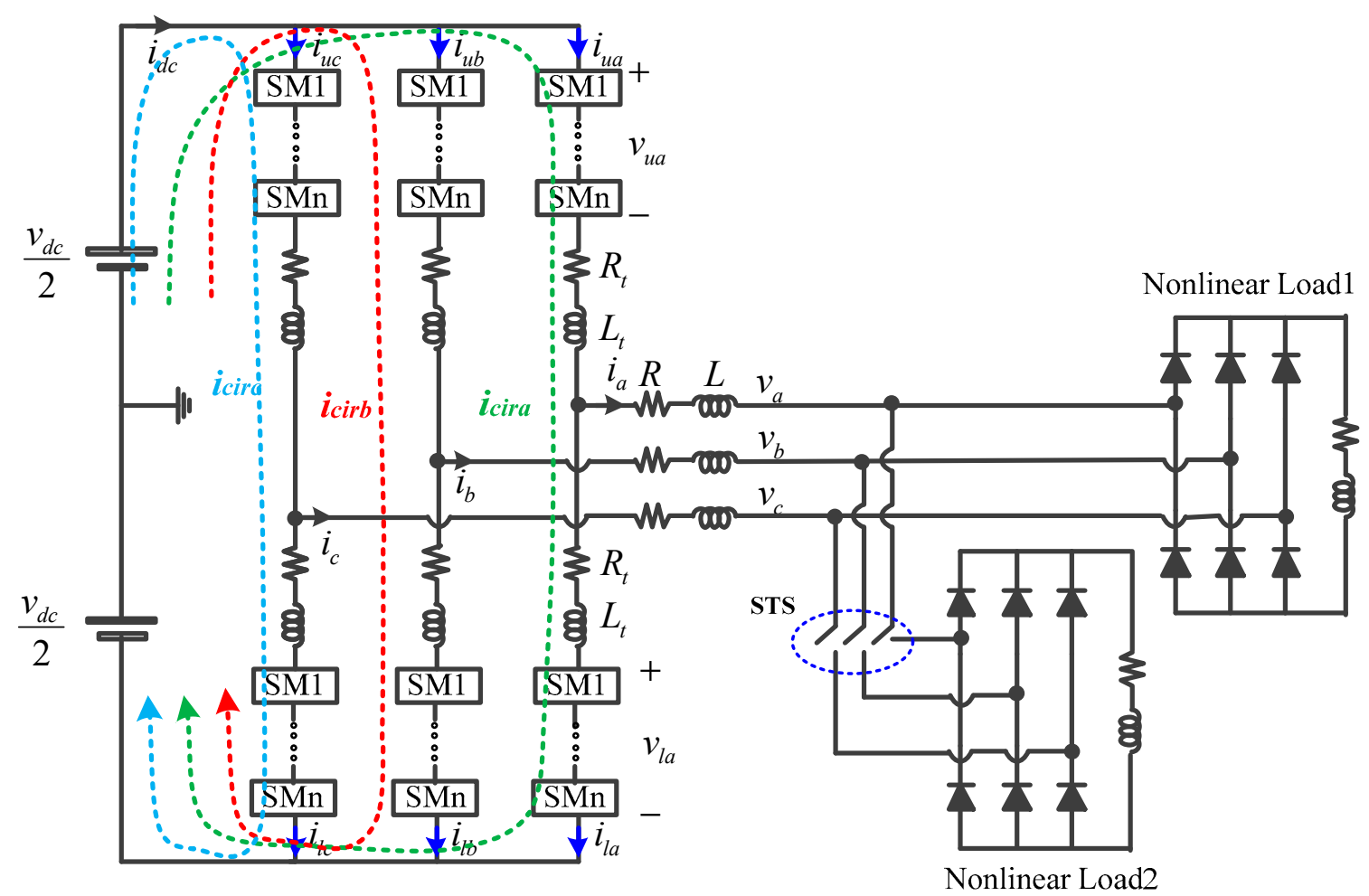

Figure 1. The configuration of the modular multilevel converter (MMC) under study.

It can be deduced from (2) that the circulating current is dependent on the upper and lower currents as well as the dc link current, which all are depicted in Figure 1. As previously stated, the control laws of the MMC in the a-b-c reference frame are defined as $v_{u k}$ and $v_{l k}$. The accurate dynamic relations between the control laws and other MMC variables can be determined by using Kirchhoff's Voltage Laws (KVLs) in Figure 1. As a result, the following dynamic equations are given:

$$
\begin{gathered}
\frac{-v_{d c}}{2}+v_{u k}+L_{t} \frac{d i_{u k}}{d t}+R_{t} i_{u k}+L \frac{d i_{k}}{d t}+R i_{k}+v_{k}=0, \\
\frac{v_{d c}}{2}-v_{l k}+L_{t} \frac{d i_{l k}}{d t}+R_{t} i_{l k}+L \frac{d i_{k}}{d t}+R i_{k}+v_{k}=0 .
\end{gathered}
$$

The dynamic Equations (3) and (4) are utilized for achieving the ultimate control laws.

\section{The Proposed Control Strategies}

In order to attain proper performance for the employed PWM, considering all operating responses with the help of related dynamic models will contribute to more accurate operation for the proposed control strategies. Since the MMC works as an inverter in this paper, the worst responses with harmonic components are considered for the output currents and voltages. This means that

$$
\begin{aligned}
& v_{k}=v_{m 1} \cos \left(\omega_{1} t+n \frac{2 \pi}{3}\right)+v_{m 5} \cos \left(\omega_{5} t+n \frac{2 \pi}{3}\right)+ \\
& v_{m 7} \cos \left(\omega_{7} t+n \frac{2 \pi}{3}\right)+v_{m 11} \cos \left(\omega_{11} t+n \frac{2 \pi}{3}\right)+ \\
& v_{m 13} \cos \left(\omega_{13} t+n \frac{2 \pi}{3}\right)+\ldots=\sum_{j=1,5,7}^{\infty} v_{m j} \cos \left(\omega_{j} t+n \frac{2 \pi}{3}\right) .
\end{aligned}
$$


And

$$
\begin{aligned}
& i_{k}=I_{m 1} \cos \left(\omega_{1} t+n \frac{2 \pi}{3}+\beta_{1}\right)+I_{m 5} \cos \left(\omega_{5} t+n \frac{2 \pi}{3}+\beta_{5}\right)+ \\
& I_{m 7} \cos \left(\omega_{7} t+n \frac{2 \pi}{3}+\beta_{7}\right)+I_{m 11} \cos \left(\omega_{11} t+n \frac{2 \pi}{3}+\beta_{11}\right)+ \\
& I_{m 13} \cos \left(\omega_{13} t+n \frac{2 \pi}{3}+\beta_{13}\right)+\ldots=\sum_{j=1,5,7}^{\infty} I_{m j} \cos \left(\omega_{j} t+n \frac{2 \pi}{3}+\beta_{j}\right) .
\end{aligned}
$$

The angle difference between the output currents and voltages is determined by $\beta_{j}$. Also, the angular frequencies are defined as $\omega_{j}=j(2 \pi f)$. In addition, three states for circulating currents in relationship (2) are employed to achieve the upper and lower arm currents.

\subsection{Case 1: Zero Circulating Currents}

One of the main aims of controlling MMCs is suppressing the circulating currents as much as possible. In this subsection, zero circulating currents are assumed. Consequently, using (1), (2) and (5), (6), the upper and lower arm currents will be equivalent with (7):

$$
i_{u(l) k}=0.5 \sum_{j=1,5,7}^{\infty} I_{m j} \cos \left(\omega_{j} t+n \frac{2 \pi}{3}+\beta_{j}\right) \pm \frac{i_{d c}}{3} .
$$

According to (7), the achieved arm currents consist of harmonic components due to the output MMC currents. As a result, by substituting the relationships (5)-(7) into the dynamic Equations (3) and (4), the proposed control laws regarding to this case are:

$$
\begin{aligned}
& v_{u(l) k}=\frac{v_{d c}}{2}-L_{t} \frac{i_{d c}}{3}-R_{t} \frac{i_{d c}}{3} \\
& \pm\left(0.5 L_{t}+L\right) \sum_{j=1,5,7}^{\infty} I_{m j} \omega_{j} \sin \left(\omega_{j} t+n \frac{2 \pi}{3}+\beta_{j}\right) \\
& \mp\left(0.5 R_{t}+R\right) \sum_{j=1,5,7}^{\infty} I_{m j} \cos \left(\omega_{j} t+n \frac{2 \pi}{3}+\beta_{j}\right) \\
& \mp \sum_{j=1,5,7}^{\infty} v_{m j} \cos \left(\omega_{j} t+n \frac{2 \pi}{3}\right)
\end{aligned}
$$

Both proposed control laws in (8) will be affected by the magnitude and phase of various harmonic components of the output voltages and currents. Also, the dc-link voltage can shift the proposed control laws. The dc-link current can also contribute to the aforementioned shift. The proposed control strategy under zero circulating currents is depicted in Figure 2. According to this figure, three kinds of proportional-integral (PI) controller are utilized for regulating the magnitudes and phases of $\left\{\beta_{j}, I_{m j}, v_{m j}\right\}$ in order to reach the desired values. 


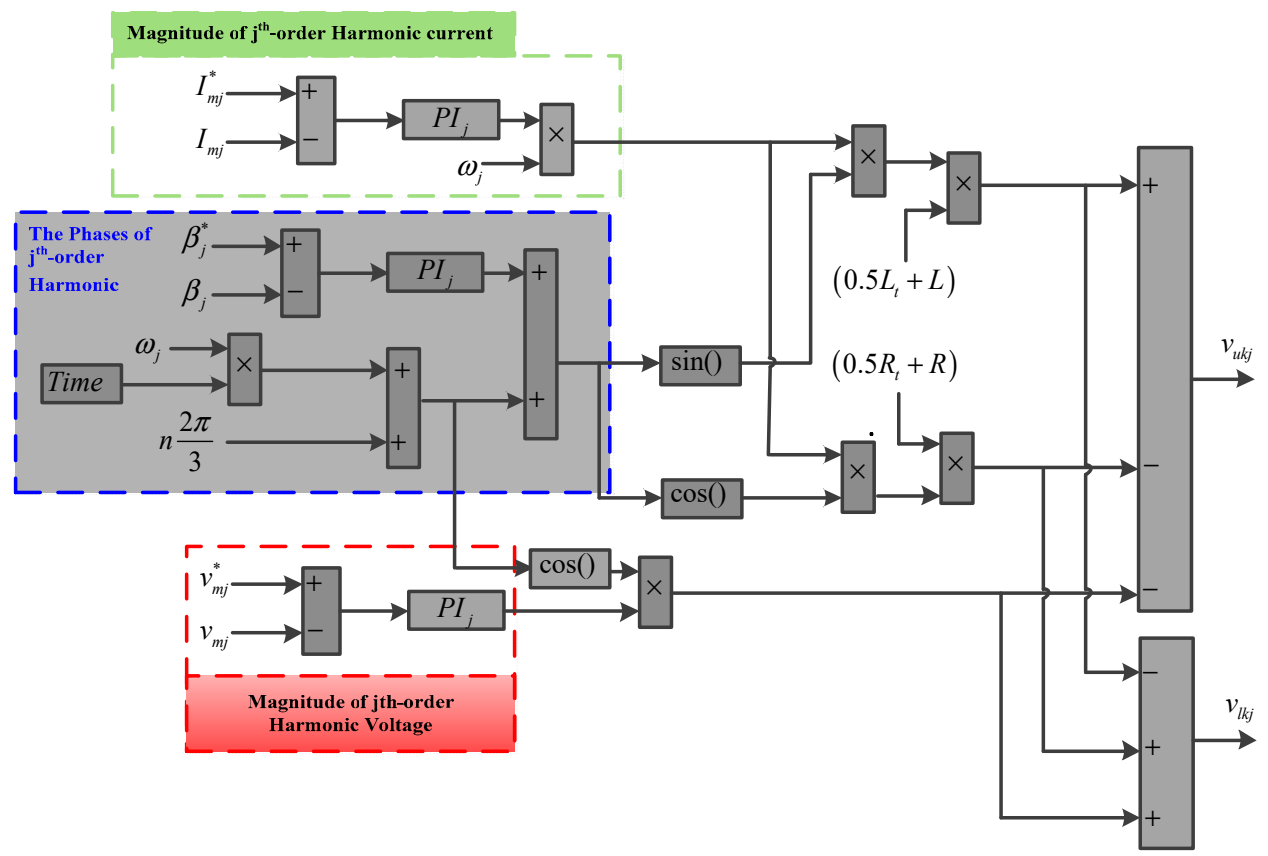

(a)

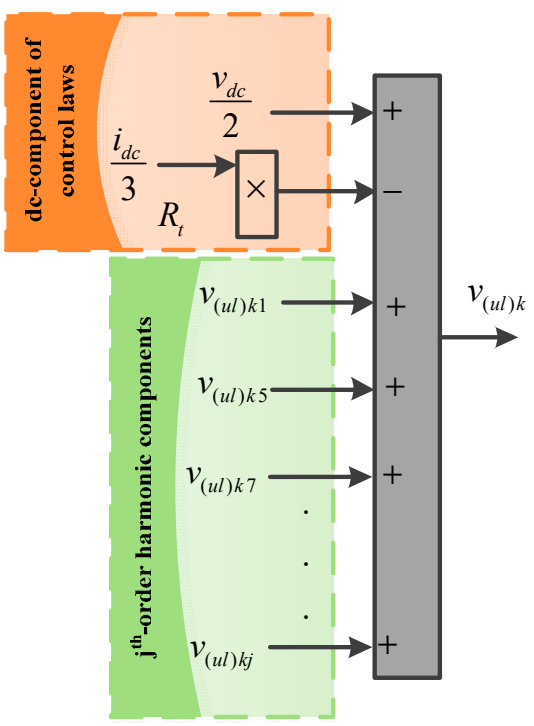

(b)

Figure 2. Proposed control strategy under zero circulating currents: (a) harmonic components of control laws and (b) the control laws.

\subsection{Case 2: Circulating Currents with a dc Component and Sinusoidal Second-Order Frequency}

More detailed circulating currents could achieve more accurate control laws for the proposed control strategy. In this subsection, the circulating currents consist of the dc component and sinusoidal second-order frequency as shown in (9):

$$
i_{c i r k}=I_{d c_{\_} c i r}+I_{m c i r 2} \cos \left(\omega_{2} t+n \frac{2 \pi}{3}+\alpha_{c i r 2}\right) .
$$


In this state, the relationships (1), (2), (6), and (9) are used to drive the following upper and lower arm currents:

$$
\begin{aligned}
& i_{u(l) k}=0.5 \sum_{j=1,5,7}^{\infty} I_{m j} \cos \left(\omega_{j} t+n \frac{2 \pi}{3}+\beta_{j}\right) \pm \\
& \frac{i_{d c}}{3} \pm I_{d c_{-} c i r} \pm I_{m c i r 2} \cos \left(\omega_{2} t+n \frac{2 \pi}{3}+\alpha_{c i r 2}\right) .
\end{aligned}
$$

As can be seen from (10), the second-order harmonic appears in both the upper and lower arm currents. This means that asymmetric currents pass through the upper and lower arms of the considered MMC that should be perceived in the proposed shift level PWM (SLPWM).

These currents can be incorporated into proposed control laws by substituting (10) into the dynamic Equations (3) and (4):

$$
\begin{aligned}
& v_{u(l) k}=\frac{v_{d c}}{2}-R_{t} \frac{i_{d c}}{3}-R_{t} I_{d c_{-} c i r}-L_{t} \frac{i_{d c}}{3} \pm\left[\left(0.5 L_{t}++L\right) \sum_{j=1,5,7}^{\infty} I_{m j} \omega_{j} \sin \left(\omega_{j} t+n \frac{2 \pi}{3}+\beta_{j}\right)\right] \\
& +L_{t} I_{m c i r 2} \omega_{2} \sin \left(\omega_{2} t+n \frac{2 \pi}{3}+\alpha_{c i r 2}\right) \mp\left[\left(0.5 R_{t}+R\right) \sum_{j=1,5,7}^{\infty} I_{m j} \cos \left(\omega_{j} t+n \frac{2 \pi}{3}+\beta_{j}\right)\right] \\
& -R_{t} I_{m c i r 2} \cos \left(\omega_{2} t+n \frac{2 \pi}{3}+\alpha_{c i r 2}\right) \mp\left[\sum_{j=1,5,7}^{\infty} v_{m j} \cos \left(\omega_{j} t+n \frac{2 \pi}{3}\right)\right] .
\end{aligned}
$$

The proposed control strategy under circulating currents with a dc component and second-order harmonic is illustrated in Figure 3. As can be deduced from this figure, the harmonic components of the designed control technique are divided in two parts. The first part belongs to the same harmonic components as those due to zero circulating currents. In this part, the MMC output currents and voltages cause these harmonic components.

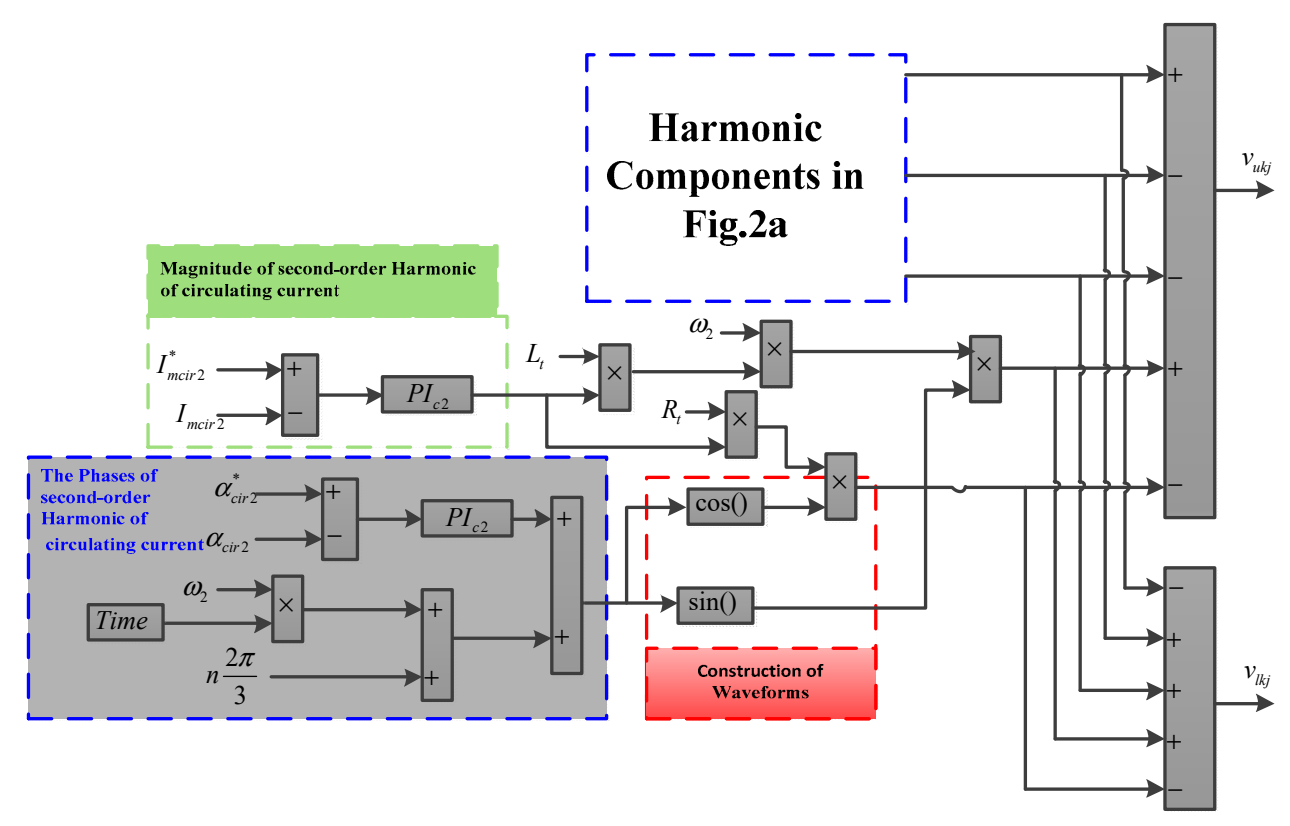

(a)

Figure 3. Cont. 


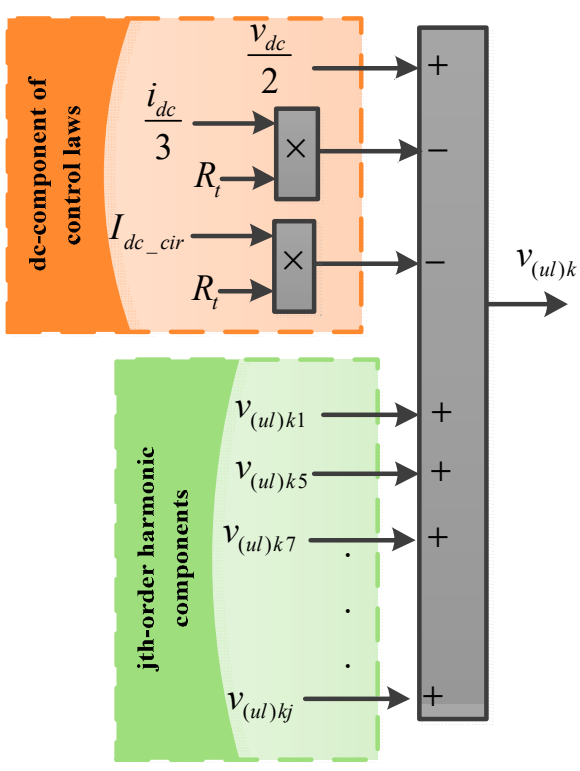

(b)

Figure 3. Proposed control strategy under circulating currents with a dc component and second-order frequency sinusoid: (a) harmonic components of control laws and (b) the control laws.

The second part is formed by the second-order harmonic for circulating current, as depicted in Figure 3. In addition, the dc component of circulating currents will impact on the proposed control laws according to Figure $3 \mathrm{~b}$. More detailed circulating currents used in the proposed control laws can lead to more accurate PWM reference waveforms.

\subsection{Case 3: Circulating Currents with Harmonic Distortions}

In addition to the second-order harmonic, harmonic distortions with various frequencies are assumed as the worst-case scenario for circulating currents in this subsection.

The considered circulating currents can be written as (12):

$$
i_{\text {cirk }}=I_{d c_{\_} c i r}+\sum_{j=1,2,5,7}^{\infty} I_{m c i r j} \cos \left(\omega_{j} t+n \frac{2 \pi}{3}+\alpha_{\text {cirj }}\right) \text {. }
$$

After some mathematical calculations with the help of relationships (1), (2), (6), and (12), the upper and lower arm currents are obtained as the following:

$$
\begin{aligned}
& i_{u(l) k}=0.5 \sum_{j=1,3,7}^{\infty} I_{m j} \cos \left(\omega_{j} t+n \frac{2 \pi}{3}+\beta_{j}\right) \pm \frac{i_{d c}}{3} \\
& +I_{d c \_c i r} \pm \sum_{j=1,2,5,7}^{\infty} I_{m c i r j} \cos \left(\omega_{j} t+n \frac{2 \pi}{3}+\alpha_{c i r j}\right) .
\end{aligned}
$$

According to (13), all harmonic components of the circulating currents emerge in both the upper and lower arm currents. Using (3) and (4), the aforementioned upper and lower currents can be used to design the control laws in (14): 


$$
\begin{aligned}
& v_{u(l) k}=\frac{v_{d c}}{2}-R_{t} \frac{i_{d c}}{3}-R_{t} I_{d c_{c} c i r}-L_{t} \frac{i_{d c}}{3} \\
& \pm\left(0.5 L_{t}+L\right) \sum_{j=1,3,7}^{\infty} I_{m j} \omega_{j} \sin \left(\omega_{j} t+n \frac{2 \pi}{3}+\beta_{j}\right) \\
& +L_{t} \sum_{j=1,2,5,7}^{\infty} I_{m c i r j} \omega_{j} \sin \left(\omega_{j} t+n \frac{2 \pi}{3}+\alpha_{c i r j}\right) \mp\left(0.5 R_{t}+R\right) \\
& \times \sum_{j=1,3,7}^{\infty} I_{m j} \cos \left(\omega_{j} t+n \frac{2 \pi}{3}+\beta_{j}\right)-R_{t} \sum_{j=1,2,5,7}^{\infty} I_{m c i r j} \\
& \times \cos \left(\omega_{j} t+n \frac{2 \pi}{3}+\alpha_{c i r j}\right) \mp \sum_{j=1,5,7}^{\infty} v_{m j} \cos \left(\omega_{j} t+n \frac{2 \pi}{3}\right)
\end{aligned}
$$

Based on the achieved control laws (14), the proposed control strategy under circulating currents with harmonic distortions is expressed by Figure 4. As can be seen from Figure 4a, the proposed control laws are highly affected by the various harmonic components of the circulating currents. Two additional kinds of PI controllers are employed in this part to provide more appropriate control in such operating conditions.

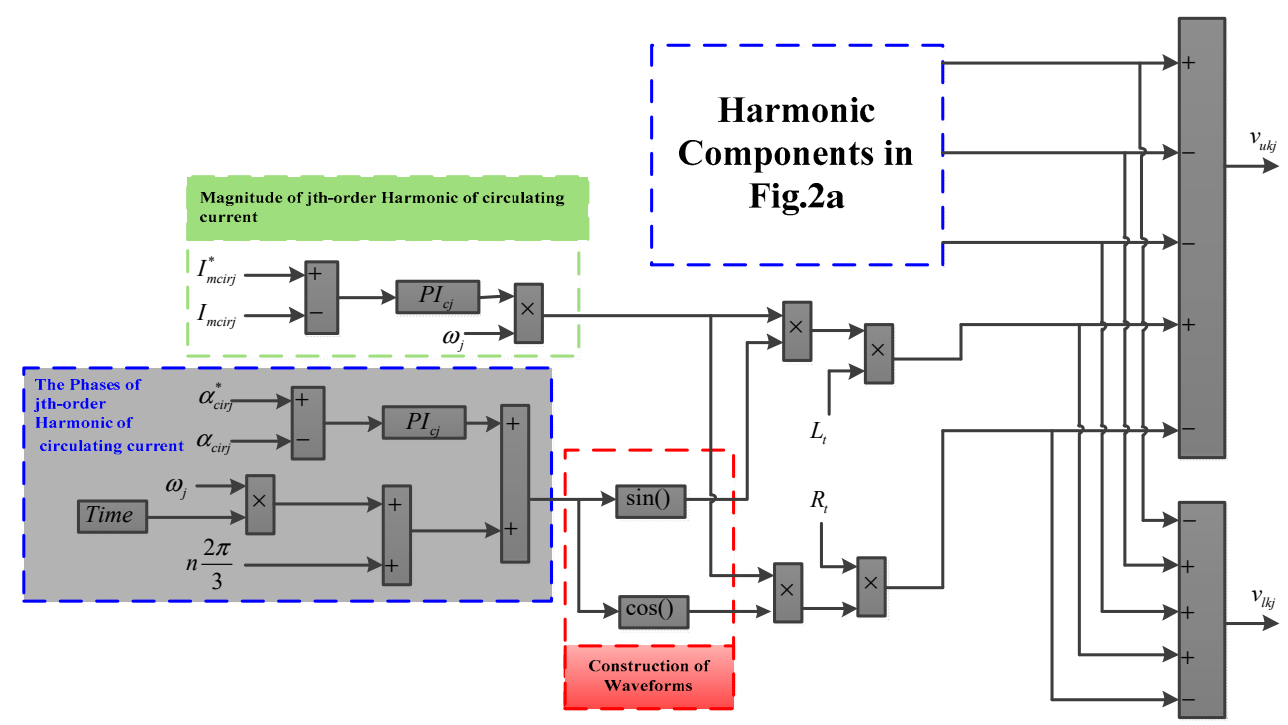

(a)

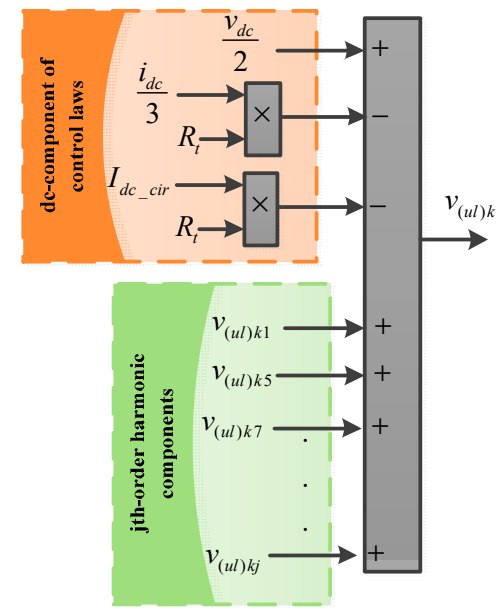

(b)

Figure 4. Proposed control strategy under circulating currents with harmonic distortions: (a) harmonic components of control laws and (b) the control laws. 


\section{Evaluation of the Proposed Control Laws}

The proposed control laws have a key role in reaching stable responses of the MMC under study. In this section, the three proposed control laws are compared to each other. Using the parameters in Table 1, the upper and lower control laws given in (8), (11), and (14) are drawn in Figure 5.

Table 1. The parameters of the proposed MMC in load change conditions.

\begin{tabular}{cccc}
\hline Parameters & Value & Parameters & Value \\
\hline MMC Inductance $(\mathrm{H})$ & $1 \times 10^{-3}$ & SM Number & 10 \\
MMC resistance $(\mathrm{Ohm})$ & 1 & Fundamental Frequency $(\mathrm{Hz})$ & 60 \\
MMC Arm Inductance $(\mathrm{H})$ & $2.5 \times 10^{-3}$ & Switching Frequency $(\mathrm{kHz})$ & 20 \\
MMC Arm Resistance $(\mathrm{Ohm})$ & 0.1 & The Impedance of First Nonlinear Load (Ohm) & 81 \\
SM Voltage $(\mathrm{V})$ & 40 & The Impedance of Second Nonlinear Load (Ohm) & 92 \\
dc-Link Voltage $(\mathrm{V})$ & 400 & Maximum Output Voltage (V) & 200 \\
\hline
\end{tabular}

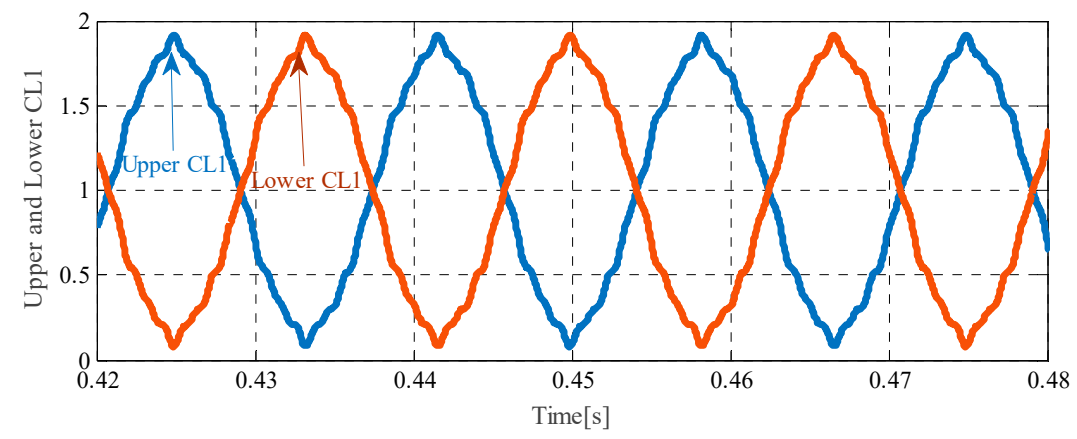

(a)

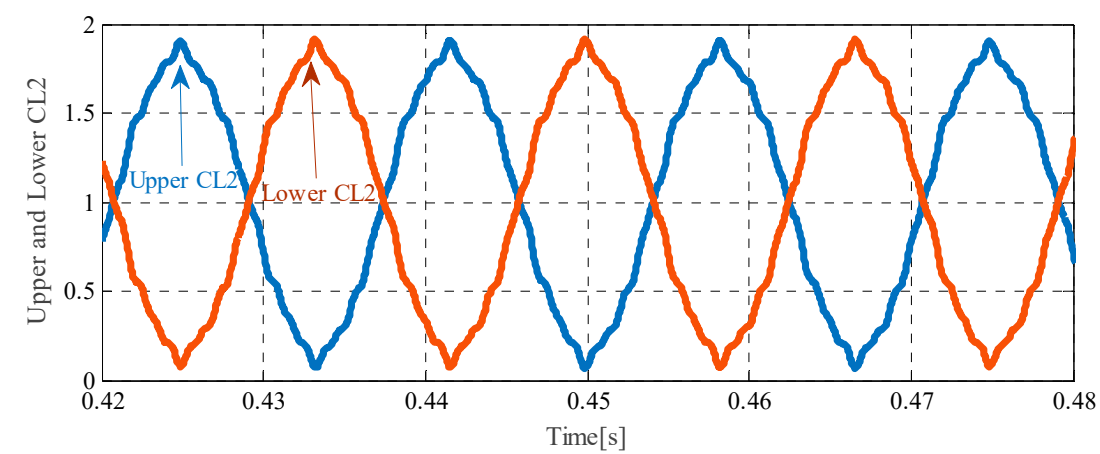

(b)

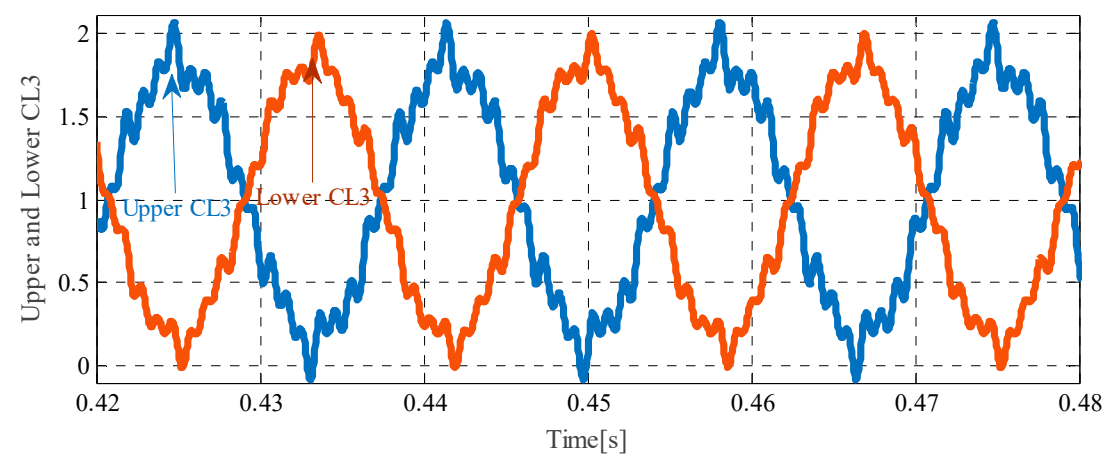

(c)

Figure 5. The proposed upper and lower control laws (CL) for the (a) first controller, (b) second controller, and (c) third controller. 
All figures were obtained without the harmonic compensation. Under zero circulating currents, the proposed control laws of phase "a" are shown in Figure $5 \mathrm{a}$. Since the magnitude of the second-order harmonic of circulating current used for drawing Figure $5 \mathrm{~b}$ is considered small, the two figures of Figure $5 \mathrm{a}, \mathrm{b}$ seem to be the same. As can be seen from this figure, the harmonic components of the output currents and voltages cause the control laws to have waveforms with greater nonlinearity. On the other hand, the harmonic components due to the circulating currents generate control laws with more distortions, as shown in Figure $5 \mathrm{c}$. In addition, the existence of the harmonic components in the circulating currents can raise the magnitude of the control laws by more than 2, leading to SLPWM with over-modulation, as depicted in Figure $5 \mathrm{c}$. Also, according to this figure, a negative magnitude is achieved for the third upper control laws. From Figure $5 \mathrm{a}, \mathrm{b}$, it seems that both the first and second control laws have similar waveforms. In practice, the effect of the second-order harmonic component of the circulating currents can be realized by making a comparison between the switching signals.

Figure 6 shows a 10-level shifted PWM used for the considered MMC with 10 SMs in each arm. Based on this figure, each triangle waveform is employed for its corresponding SM. By use of the 10-level triangle waveforms given in Figure 6, the SLPWM strategy was applied to the first and second control laws of phase "a" in Figure 5a,b, respectively. In comparison with the switching signals of the first control laws in Figure 7a, more switching operations are executed by the second control-law-based SLPWM, as depicted in Figure $7 \mathrm{~b}$. More switching operations causes greater switching losses. Thus, if a second-order harmonic component exists in the MMC circulating currents, the MMC switching losses are noticeably increased.

To further assess the switching signals, a distributed pattern of switching signals was driven by the third control-law-based SLPWM, as demonstrated by Figure 7c. In comparison with the switching signals of the first control laws in Figure 7a, inappropriate switching signals were achieved by the third control laws, as shown in Figure 7c. Furthermore, due to the over-modulation condition caused by the harmonic components of circulating currents, the third control laws cannot provide accurate switching signals in a certain operating period.

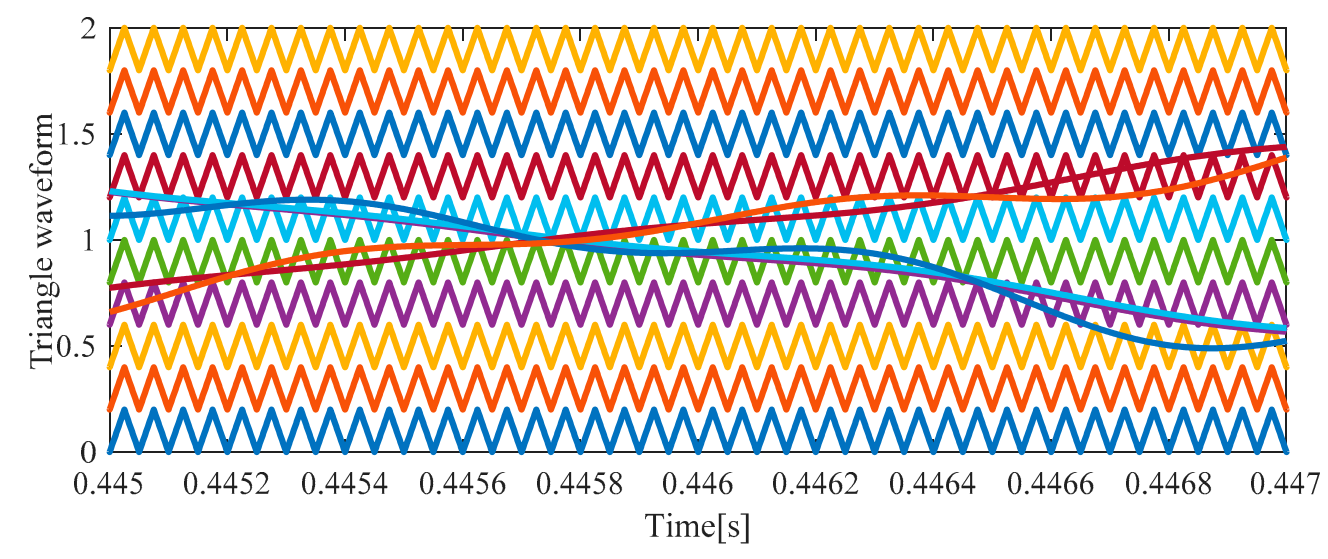

Figure 6. The 10-level triangle waveforms used. 

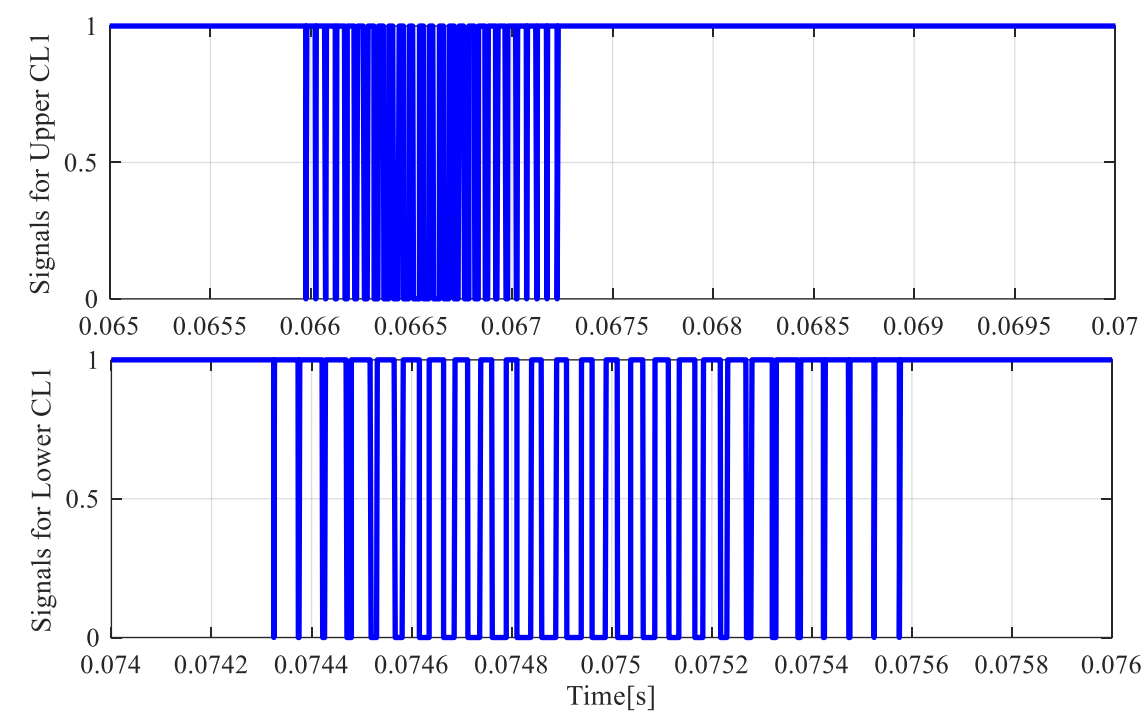

(a)
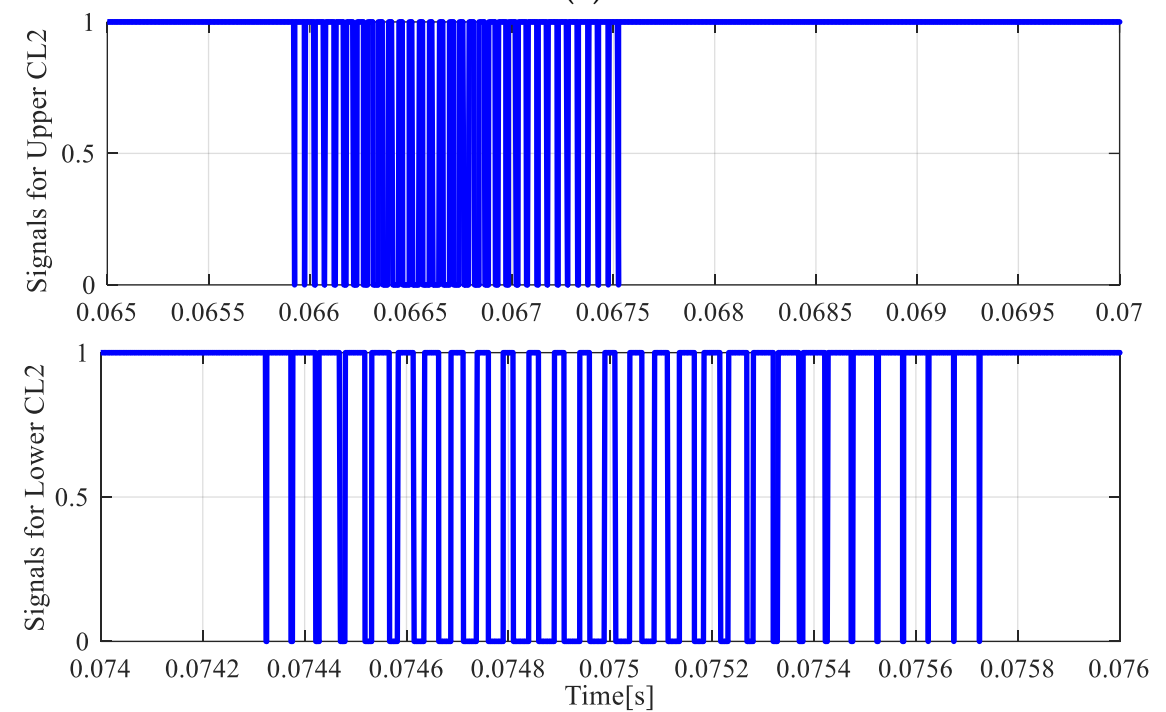

(b)
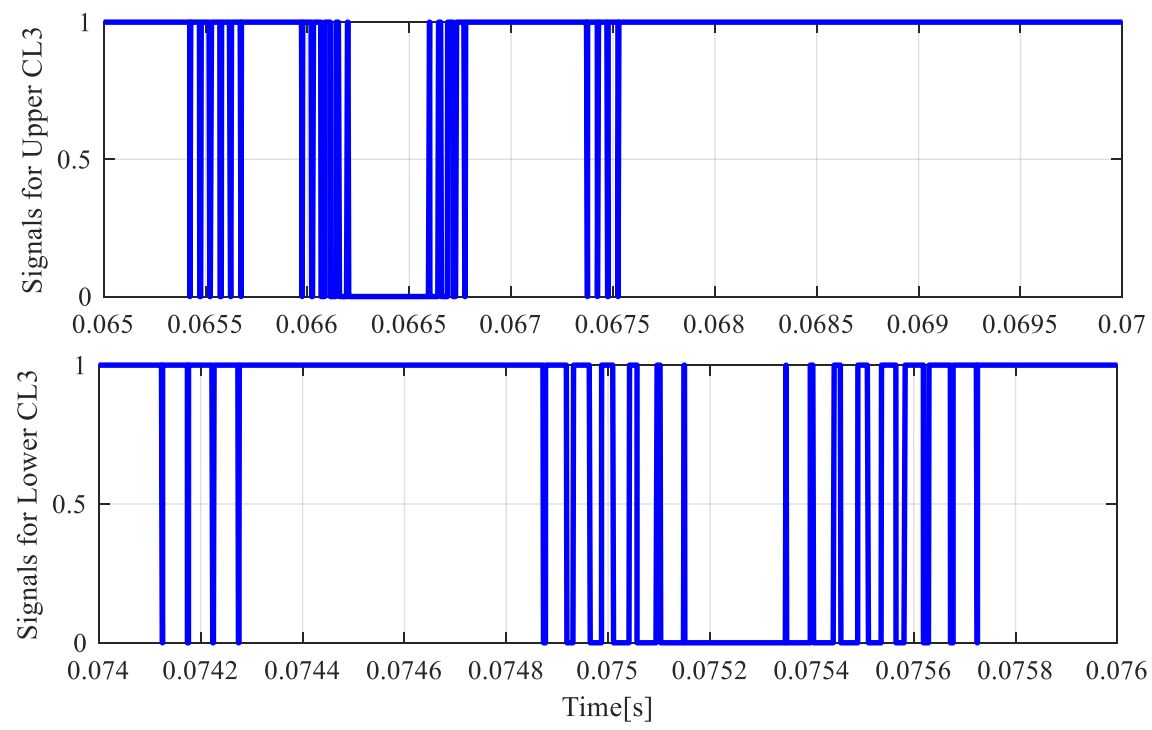

(c)

Figure 7. The signals of upper and lower switches of the MMC for the (a) first controller, (b) second controller, and (c) third controller. 


\section{Accurate Sizing of the Equivalent SM Capacitors of the MMC Arms}

Each MMC arm has its own equivalent capacitor. To accurately determine the size of this capacitor, the voltage across all SM capacitors and the current flows in each arm must be analyzed. According to the proposed control strategies discussed in Section 2, three equivalent capacitors can be obtained. The basic relationship between the arm currents and the voltages across the SM capacitors is written as (15):

$$
i_{u(l) k}=C_{u(l) k} \frac{d v_{u(l) k}}{d t} .
$$

For the first control techniques, it was assumed that the circulating current is equal to zero. Thus, by substituting (7) and (8) into (15), the equivalent capacitor of the SMs in each arm for the first control techniques can be represented as follows:

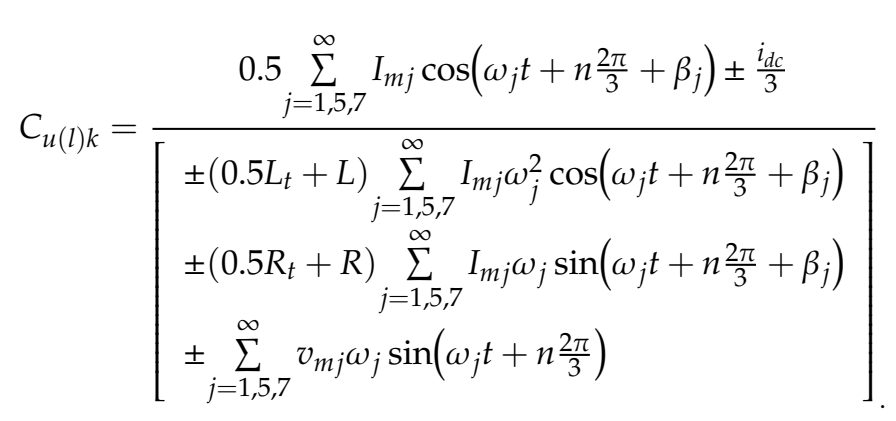

The same scenario was applied to the second and third control techniques. After substituting the relationships (10), (11) and (13), (14) into (15) and performing some mathematical calculations, the equivalent capacitors of the SMs in each arm for the second and third cases were derived as (17) and (18), respectively.

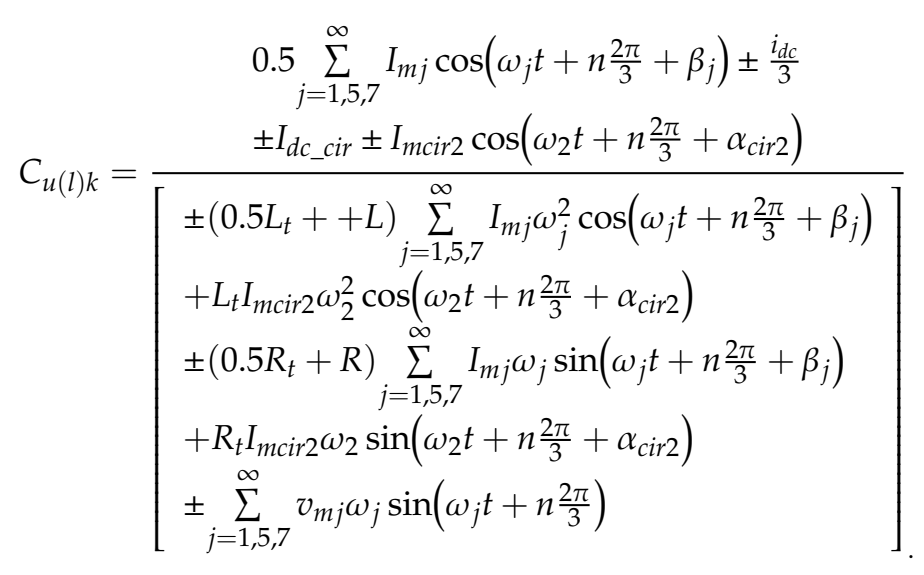




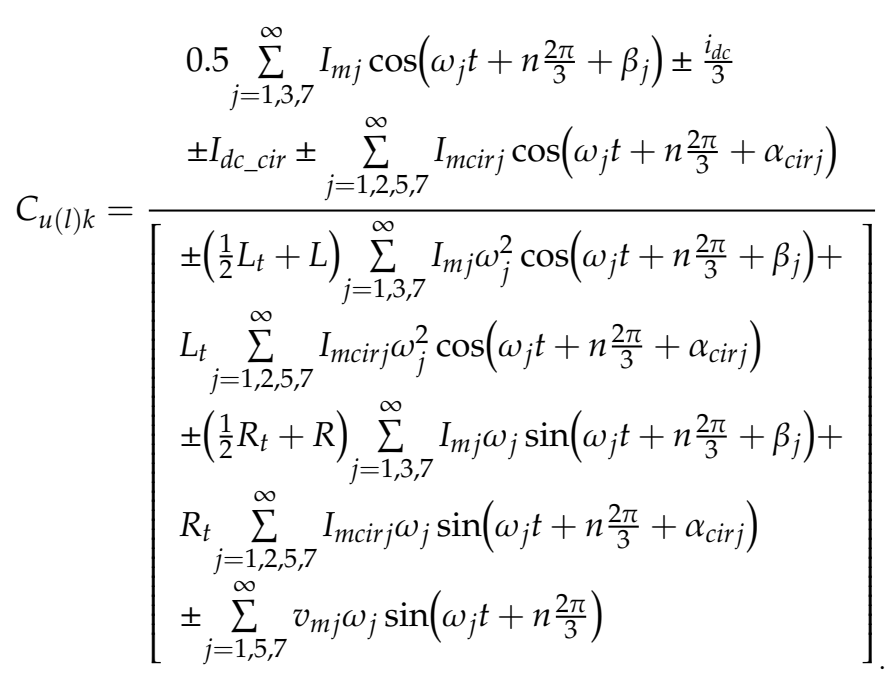

Figures 8 and 9 illustrate the time-based variations of the equivalent capacitors of the upper and lower SMs for the three proposed control strategies, along with their zoom fragments. It can be understood from Figure 8b,c that the upper arm equivalent capacitors for the second and third proposed control strategies tend to reach greater magnitudes when compared to the first proposed controller. In other words, the upper equivalent capacitor of the first proposed controller shown in Figure 8a shows fluctuations with smaller magnitudes.

Moreover, several fluctuations with much greater magnitudes, around 3.1 F, are seen in the upper equivalent capacitor of the second proposed controller, depicted in Figure 8b. This means that the second-order frequency component of the circulating currents dominates the equivalent capacitor magnitudes. Thus, it can be said that the elimination of this component helps the MMC approach to smaller SM equivalent capacitors.

To further analyze the lower arm equivalent capacitors of phase "a", Figure 9 is evaluated in the following. Based on Figure 9a,b, the lower equivalent capacitors of the first and second controllers attain the same results as the upper equivalent capacitors, as previously discussed from Figure $8 \mathrm{a}, \mathrm{b}$. However, the effects of other harmonic components of the circulating currents are revealed in the lower equivalent capacitor due to the third proposed control technique, as depicted in Figure 9c.

Departing from magnitudes between $0.3 \mathrm{~F}$ and $-0.2 \mathrm{~F}$, several fluctuations with high magnitudes $-1.6 \mathrm{~F}$ and $1.5 \mathrm{~F}$ appear in the lower equivalent capacitor due to the third proposed controller, as shown in Figure 9c. It can be concluded from this discussion that the elimination of harmonic components causes the MMC to require smaller SM equivalent capacitors in order to reach the desired state variables.
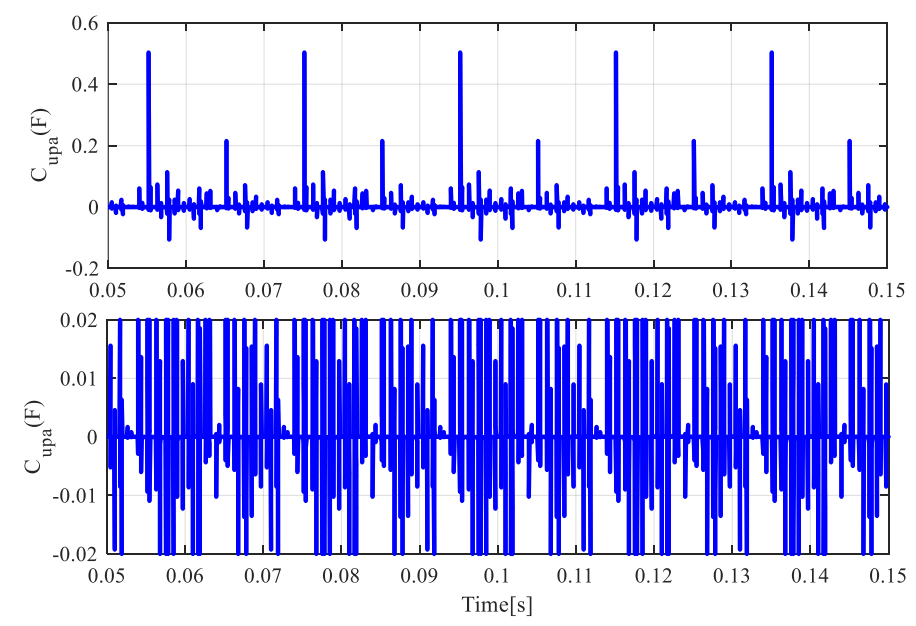

(a)

Figure 8. Cont. 

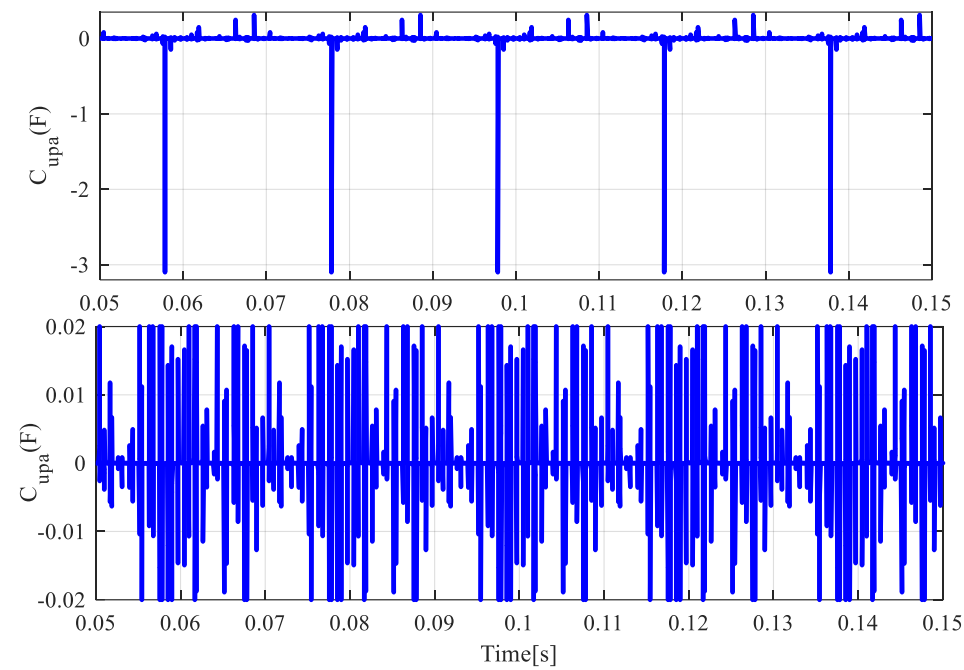

(b)

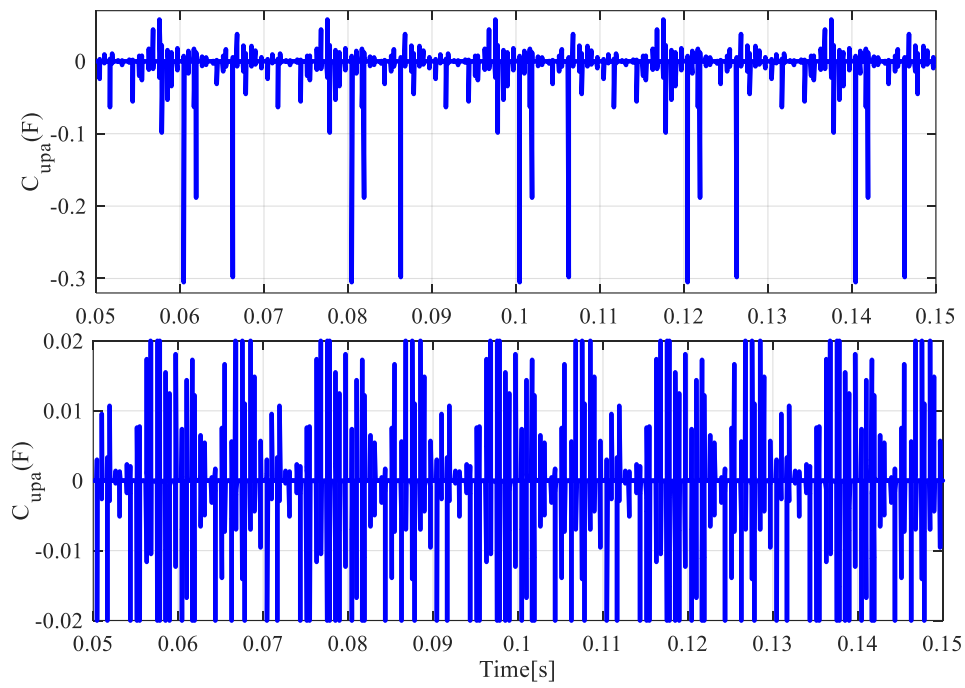

(c)

Figure 8. Equivalent capacitors for the upper arm of phase "a": (a) first controller, (b) second controller, and (c) third controller.

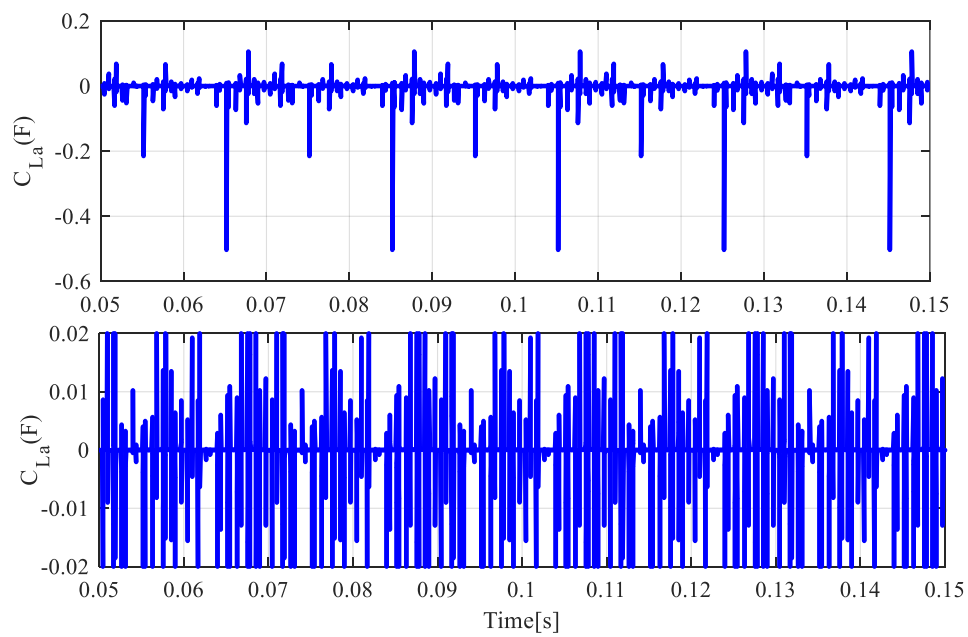

(a)

Figure 9. Cont. 

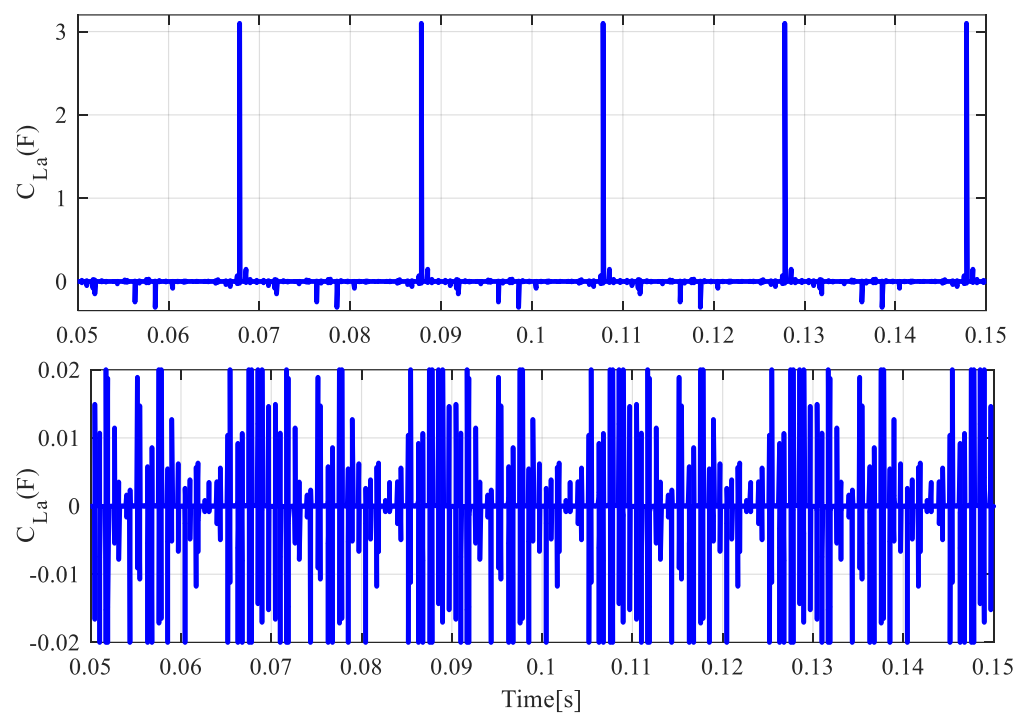

(b)
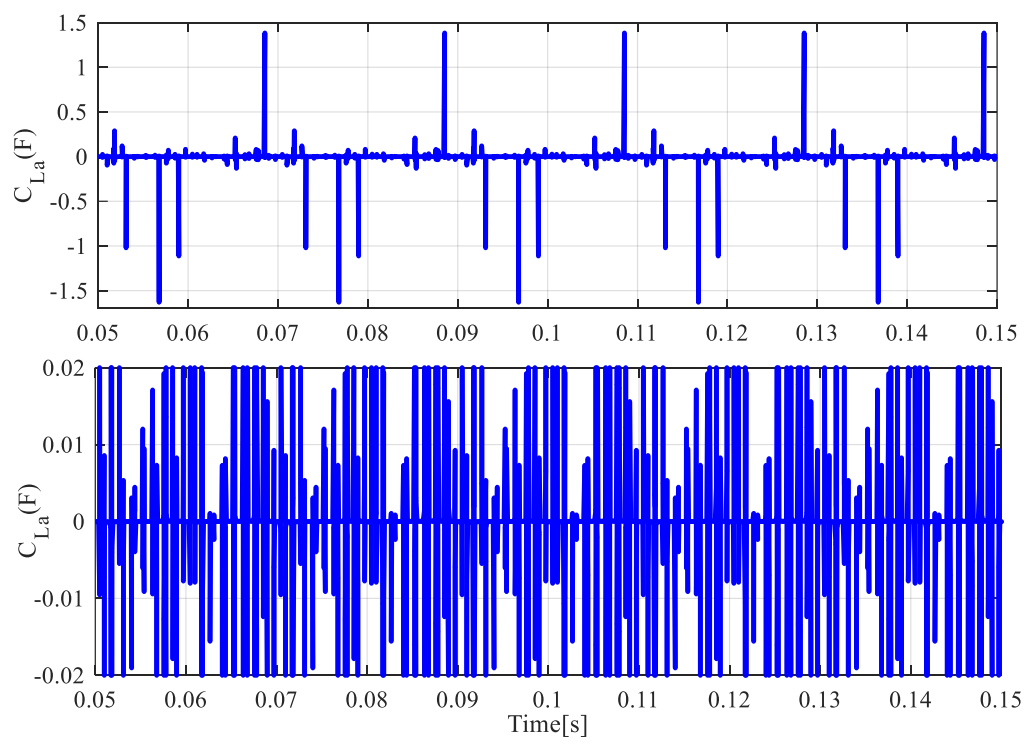

(c)

Figure 9. Equivalent capacitors for the lower arm of phase "a": (a) first controller, (b) second controller, and (c) third controller.

\section{Simulation Results}

The three proposed control strategies are compared in this section. The MMC under simulation and descriptions of the proposed control techniques are depicted in Figure 10. The parameters used are given in Table 1. As can be seen from Figure 10, two nonlinear loads were utilized for evaluating the MMC responses under both steady and dynamic conditions. The second nonlinear load was connected to the MMC at $\mathrm{t}=0.2 \mathrm{~s}$. All nonlinear loads were three-phase full-wave bridge rectifiers. Since the MMC works in stand-alone mode, a nonlinear load pollutes the output voltages, output currents, and circulating currents. The specifications of these loads are presented in Table 1. 


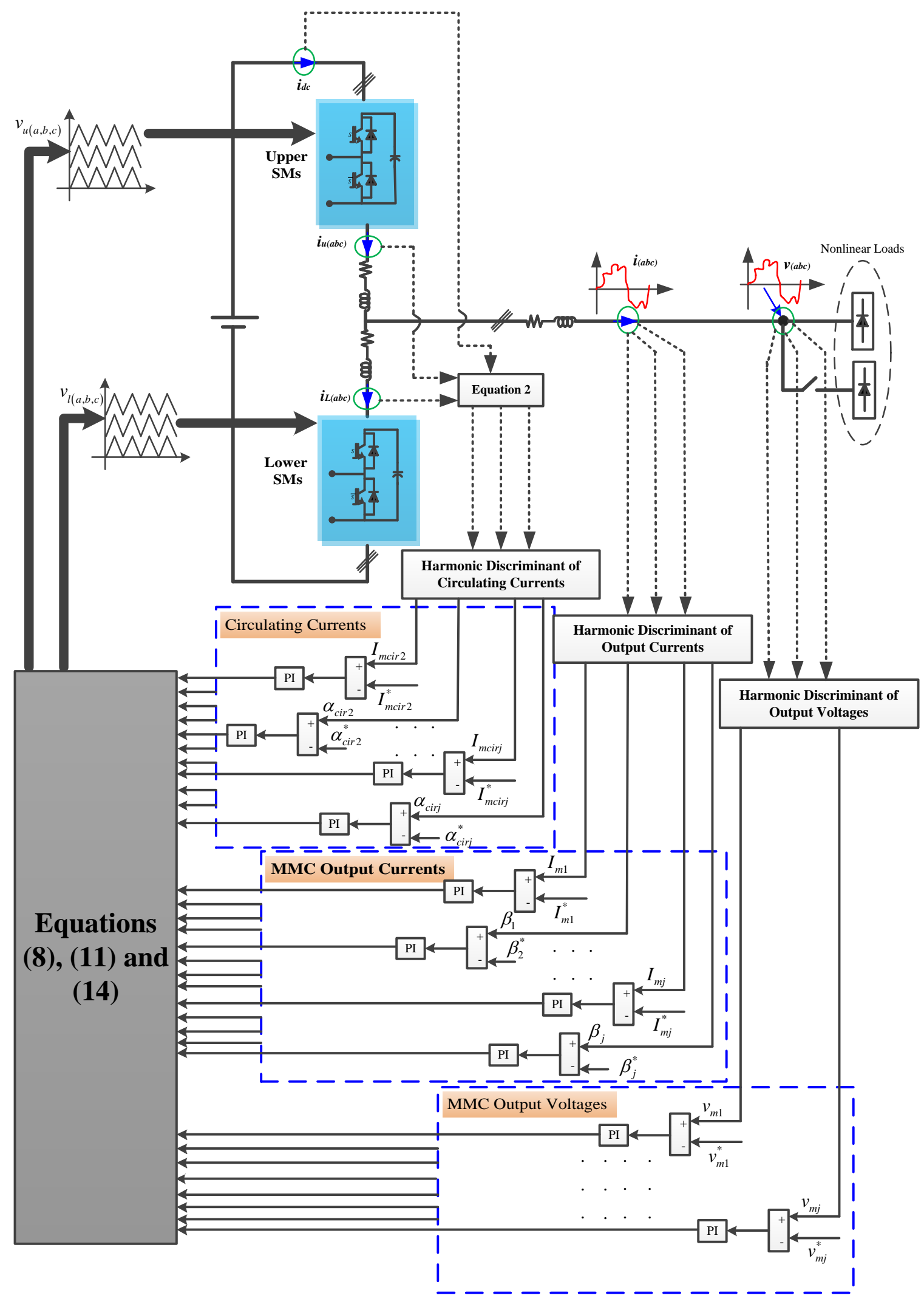

Figure 10. Overall structure of the proposed control strategies. 


\subsection{Voltage Evaluations}

In this subsection, the upper and lower SM voltages and the output voltages due to the three proposed control strategies in phase "a" are evaluated. Figure 11 exhibits the upper SM capacitor voltages of phase " $a$ " for the three proposed controllers.

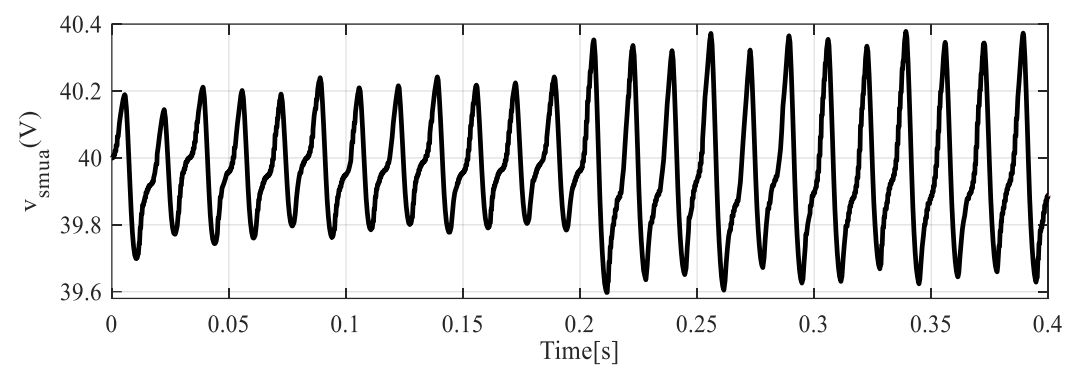

(a)

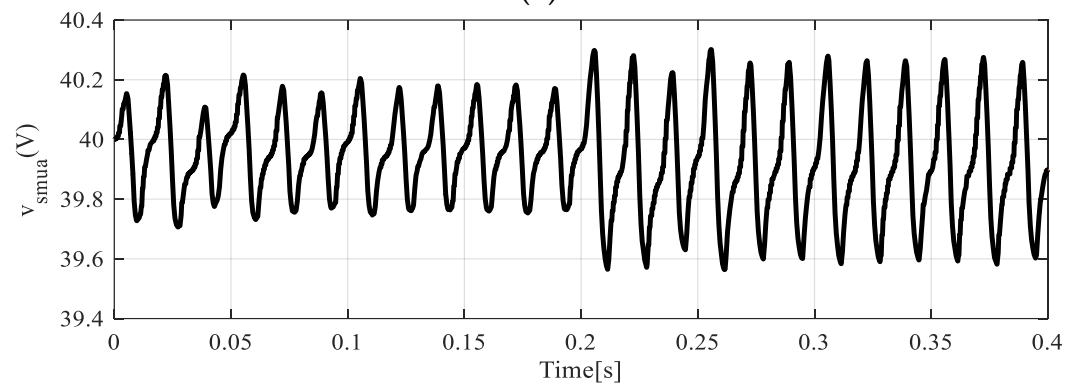

(b)

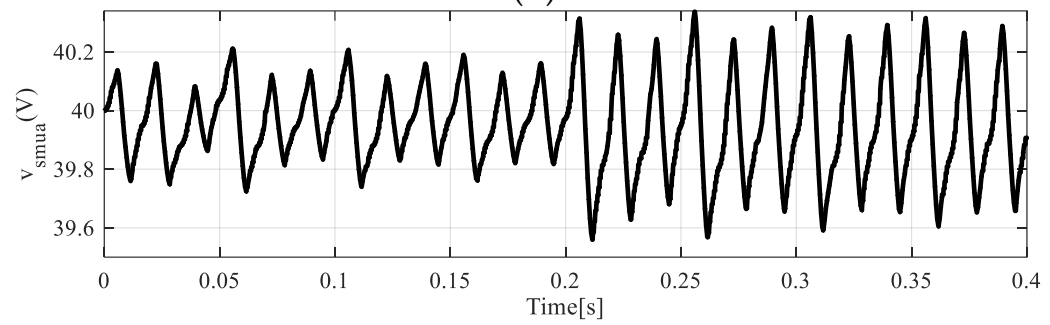

(c)

Figure 11. The upper submodule (SM) capacitor voltages of phase "a" for the (a) first controller, (b) second controller, and (c) third controller.

As can be seen from this figure, all the controllers have a good steady-state response with a similar steady error. However, after the load change at $t=0.2 \mathrm{~s}$, the third controller shows a better response with a smaller error, as depicted in Figure 11c.

This better response occurs due to the consideration of more harmonic components of circulating currents in the structure of the third proposed control technique. The same scenario happens for the lower SM capacitor voltages of phase "a" according to Figure 12.

However, in comparison with the upper SM capacitor voltage in Figure 11a which is achieved by applying the first proposed controller, the lower SM capacitor voltage shown in Figure 12a experiences higher error after the load alteration. To complete this discussion, analysis of both Figures 11 and 12 determined that the minimum and maximum SM voltage errors were $0.25 \%$ and $1.25 \%$, respectively. These errors verify the precision of the three proposed control strategies in keeping the SM voltages balanced. Another aim of the proposed control strategies was to reach the desired waveforms for the MMC output voltages. 


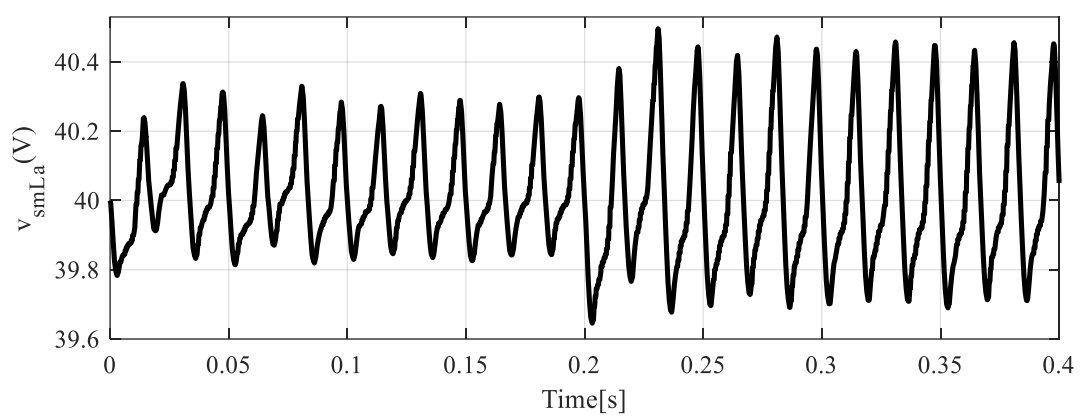

(a)

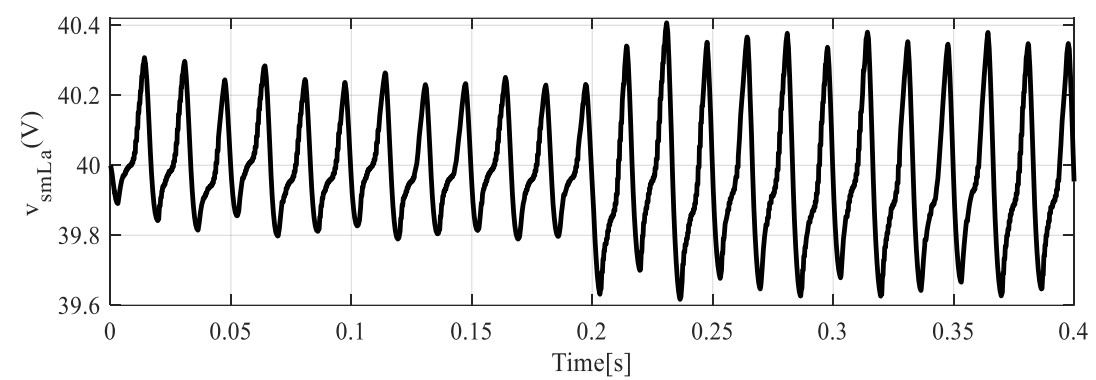

(b)

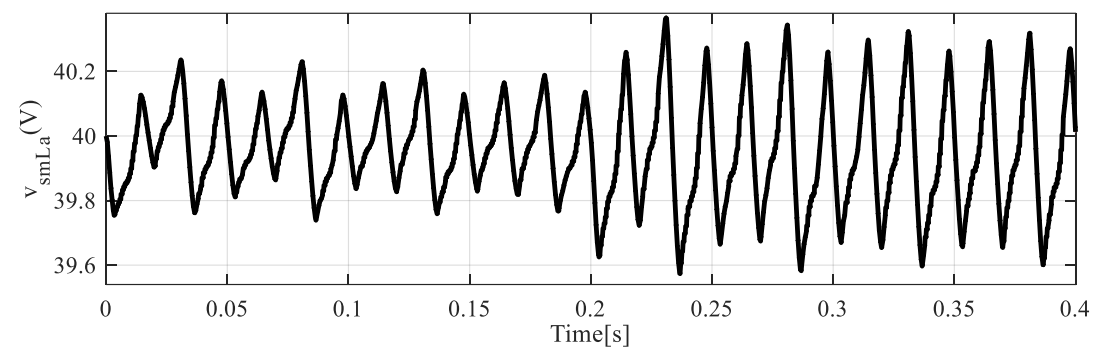

(c)

Figure 12. The lower SM capacitor voltages of phase "a" for the (a) first controller, (b) second controller, and (c) third controller.

Figure 13 demonstrates the MMC output voltages driven by the three proposed control strategies. As can be seen from Figure 13b,c, the second and third control strategies led to responses with a higher quality for the MMC output voltage when compared with the first controller in Figure 13a. The main reason for this result is the incorporation of the second-order harmonic component of circulating currents in both the second and third proposed control techniques. This means that the second-order harmonic component of the circulating currents can have a large impact on reaching the desired waveforms for MMC output voltages under both steady and dynamic state changes.

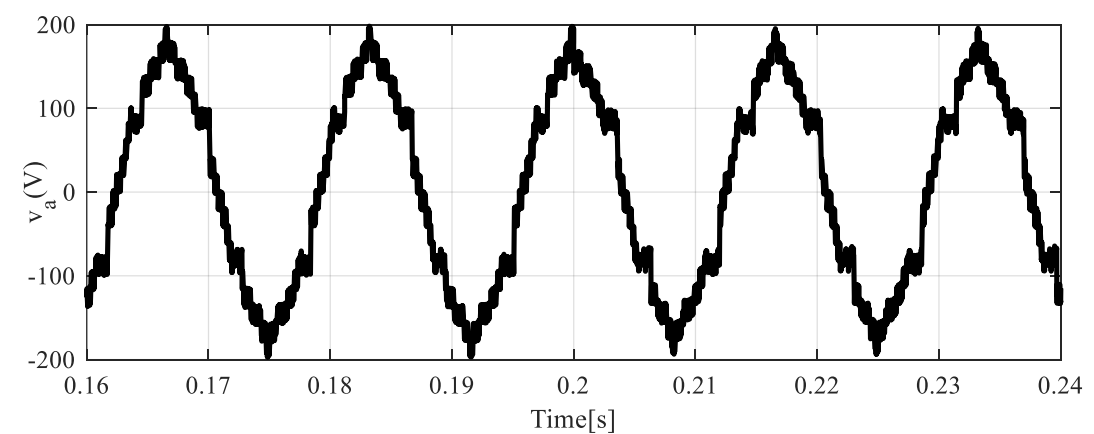

(a)

Figure 13. Cont. 


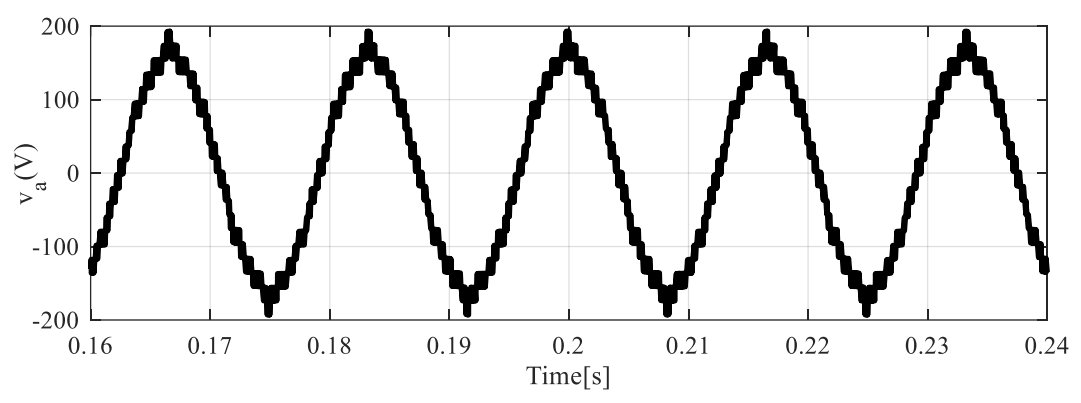

(b)

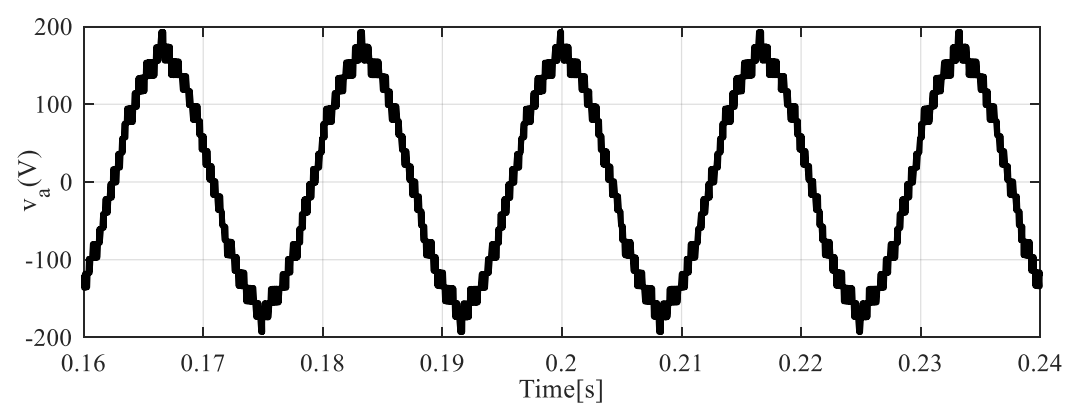

(c)

Figure 13. The output voltages of phase "a" for the (a) first controller, (b) second controller, and (c) third controller.

\subsection{Current Evaluations}

Two nonlinear loads were supplied through the MMC in this study. Figure 14 illustrates the MMC output currents which supply the loads. According to this figure, three similar nonlinear currents belonging to the three proposed controllers were produced by the MMC.

Figure 15 demonstrates the MMC circulating currents of phase "a" under load change. As predicted, the circulating current due to the third proposed control strategy was significantly smaller than the other responses, as depicted in Figure 15c.

As seen in Figure 15a, the circulating current of the first controller was more than 4 times the third controller's circulating current. On the other hand, this value deceased to more than double the third controller's circulating current for the second controller, as shown in Figure 15b. Since the third proposed controller consists of the various harmonic components of circulating currents, this controller provides a better response for circulating currents compared with the other control strategies. The effects of decreasing circulating currents can be observed in Figures 16 and 17.

Figure 16 shows the upper arm currents of phase "a" for the three proposed control strategies. As shown in Figure 16c, when the third proposed control strategy was applied to the MMC, the MMC upper arms generated less current in comparison with those under other strategies. The same scenario occurred for the MMC lower arms.

Based on Figure 17c, the MMC lower arm current showed smaller values in both steady and dynamic operating conditions. Both the MMC upper and lower arm currents generated under the first and second proposed control strategies had approximately the same results, with high values for circulating currents.

This point verifies that the control of all harmonic components of circulating currents will improve the circulating current responses under varying loads. On the other hand, when the circulating currents are increased, the upper and lower currents experience an increment in their values. This means that the arm losses will be noticeably increased, which is regarded as a drawback for the control strategy. This drawback is acceptably eliminated by the third proposed control strategy, as can be seen from Figures $16 \mathrm{c}$ and $17 \mathrm{c}$. 


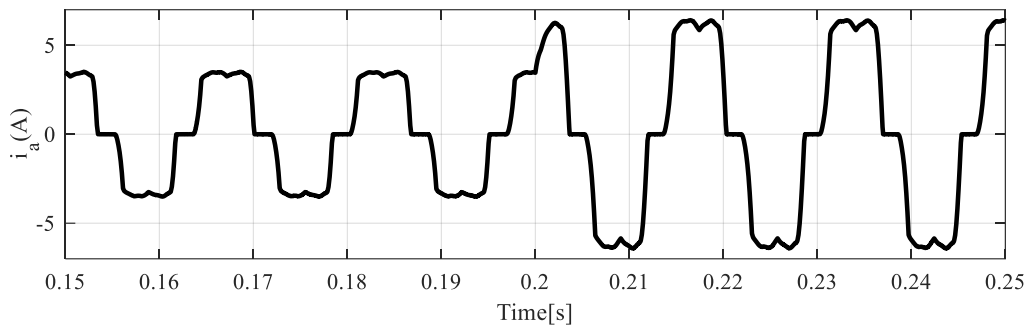

(a)

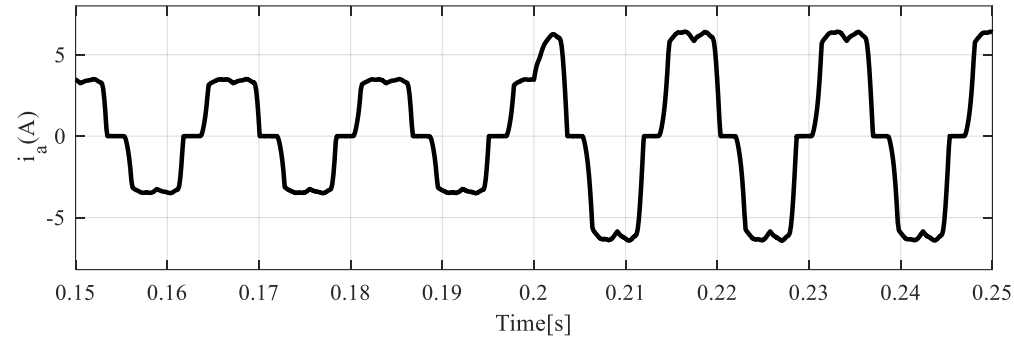

(b)

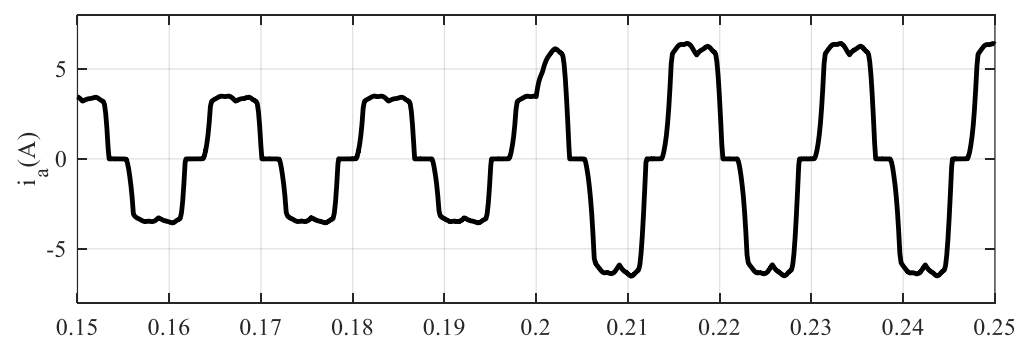

(c)

Figure 14. The output currents of phase "a" for the (a) first controller, (b) second controller, and (c) third controller.

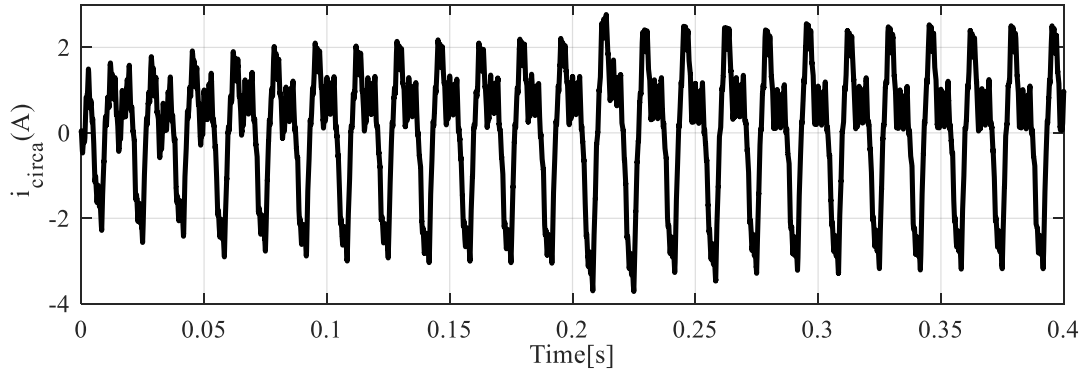

(a)

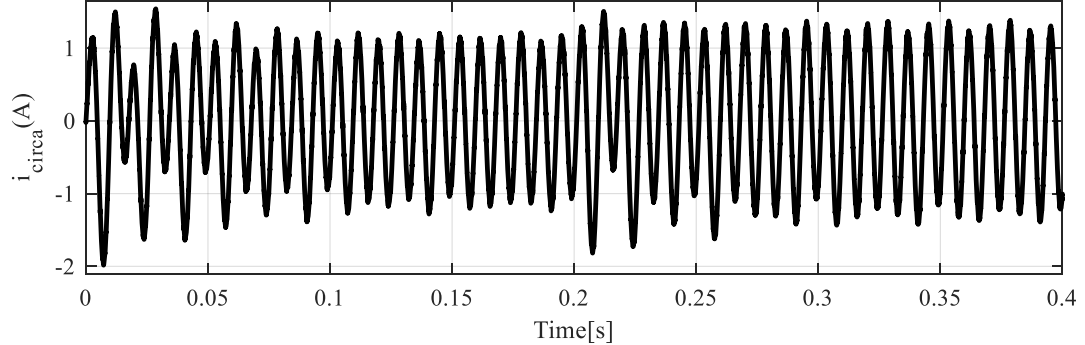

(b)

Figure 15. Cont. 


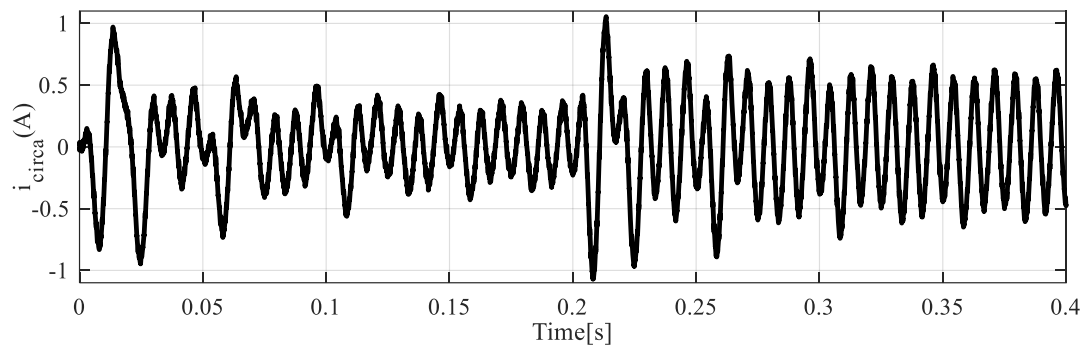

(c)

Figure 15. The circulating currents of phase " $a$ " for the (a) first controller, (b) second controller, and (c) third controller.

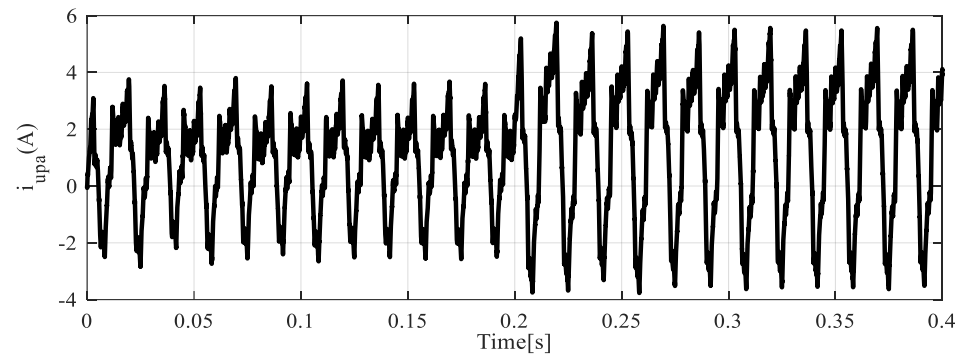

(a)

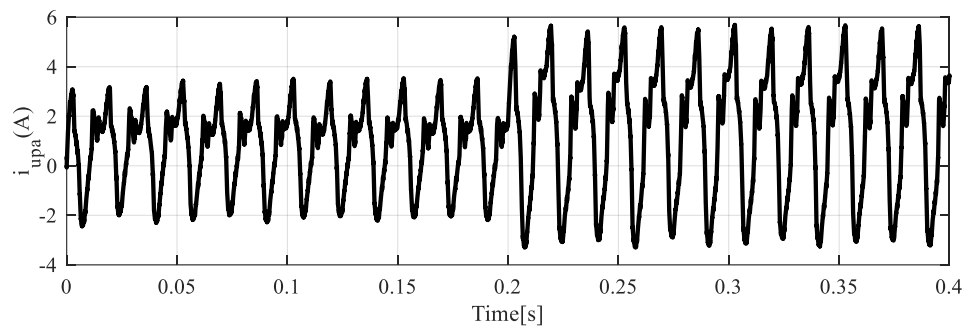

(b)

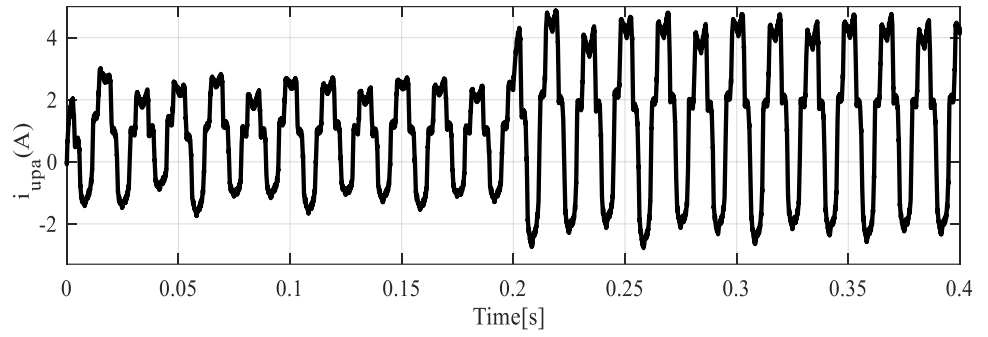

(c)

Figure 16. The upper arm currents of phase " $a$ " for the (a) first controller, (b) second controller, and (c) third controller.

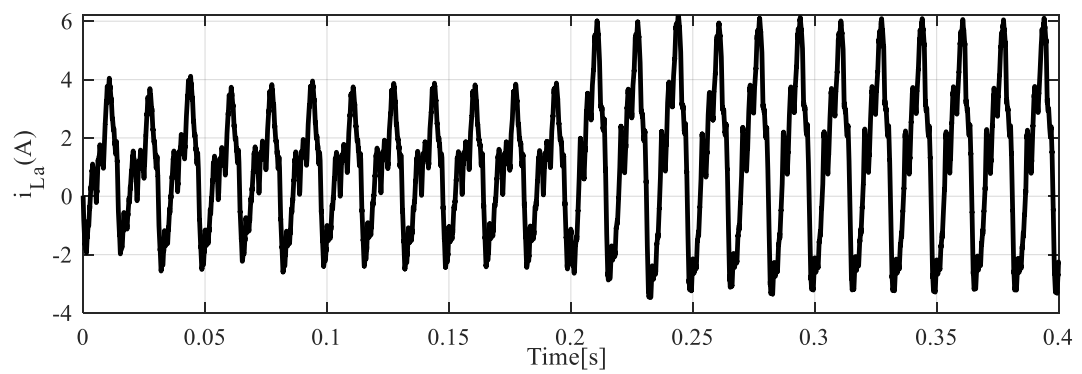

(a)

Figure 17. Cont. 


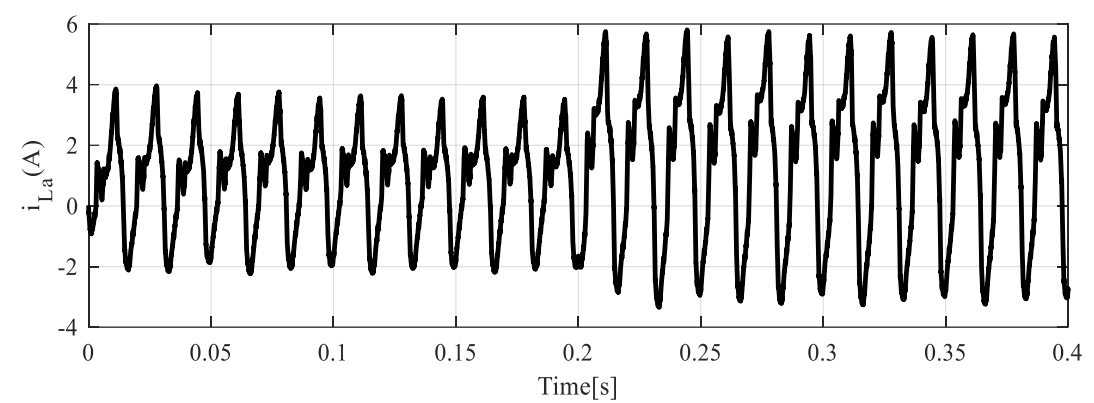

(b)

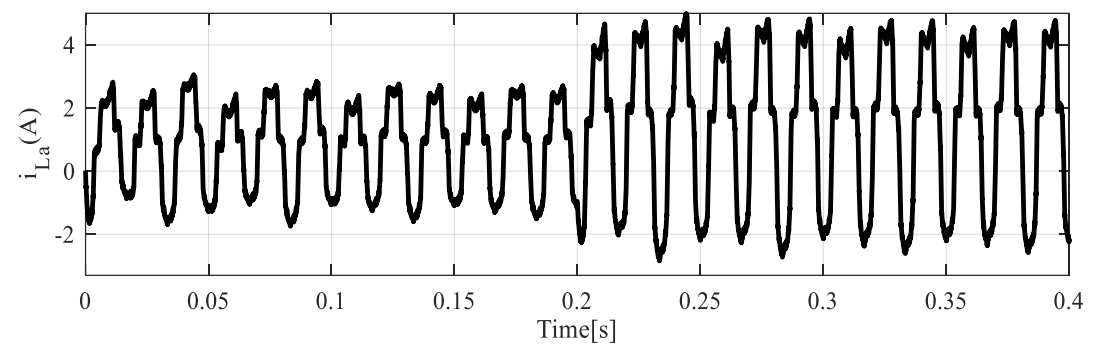

(c)

Figure 17. The lower arm currents of phase " $a$ " for the (a) first controller, (b) second controller, and (c) third controller.

To provide a complete comparison of the steady-state and dynamic performance of the three proposed control strategies, Table 2 is presented. According to this table, the smallest errors in the upper and lower capacitor voltages belong to the third proposed control strategy. In addition, the magnitude of the circulating current can be minimized by applying the third control strategy to the MMC, as demonstrated in Table 2.

Table 2. A comparison between the steady-state (SS) and dynamic (DS) performance of the three proposed control strategies.

\begin{tabular}{ccccccc}
\hline Error of & $\begin{array}{c}\text { Method1 } \\
\text { (SS) }\end{array}$ & $\begin{array}{c}\text { Method2 } \\
\text { (SS) }\end{array}$ & $\begin{array}{c}\text { Method3 } \\
\text { (SS) }\end{array}$ & $\begin{array}{c}\text { Method1 } \\
\text { (DS) }\end{array}$ & $\begin{array}{c}\text { Method2 } \\
\text { (DS) }\end{array}$ & $\begin{array}{c}\text { Method3 } \\
\text { (DS) }\end{array}$ \\
\hline Upper capacitor voltage & $1.55 \%$ & $1.25 \%$ & $1.09 \%$ & $2 \%$ & $1.625 \%$ & $1.34 \%$ \\
Lower capacitor voltage & $1.3 \%$ & $1.252 \%$ & $1.125 \%$ & $2.25 \%$ & $2.02 \%$ & $2.01 \%$ \\
Circulating current magnitude & {$[-3,2.1]$} & {$[-1.35,1.15]$} & {$[-0.7,0.6]$} & {$[-3.9,2.4]$} & {$[-1.5,1.3]$} & {$[-0.86,0.7]$} \\
\hline
\end{tabular}

\section{Conclusions}

In this paper, we designed three nonlinear PWM-based control strategies to eliminate MMC circulating currents, keeping the MMC stable under varying nonlinear loads. The MMC output currents and voltage harmonics were utilized to drive the first control law. Then, the control parts pertaining to the circulating currents' second-order harmonic were added to the first control law, leading to the proposed second control law. The third control law was designed by controlling the magnitudes and phase angles of all circulating current harmonics to force them to become practically zero. By assessing the switching signals under the proposed control laws, it was proved that the second-order and other harmonics caused an increment in MMC losses and decrement in the MMC lifetime, respectively. In addition, using the proposed control laws, the instantaneous equivalent SM capacitors were obtained. It was intended for each arm to have its own special capacitor in which the average and fluctuation values of these capacitors were noticeably decreased by the elimination of the harmonics of the circulating currents through the proposed control laws. The simulation results in MATLAB/SIMULINK software clearly demonstrated that the third control-law-based method provided better steady and 
dynamic responses for all MMC currents and voltages when compared to the other two control techniques by its ability to control all harmonic components of the circulating currents.

Author Contributions: M.M.: Writing the manuscript and simulation; E.P.: conceptualization and methodology; R.G.: editing and data analyzing; E.M.G.R.: editing and funding, J.P.S.C.: editing and supervision. All authors have read and agreed to the published version of the manuscript.

Funding: This research received no external funding.

Acknowledgments: The authors gratefully acknowledge the contributions of Amir Ganjavi. Radu Godina acknowledges Fundação para a Ciência e a Tecnologia (FCT-MCTES) for its financial support via the project UIDB/00667/2020 (UNIDEMI). J.P.S. Catalão acknowledges the support by FEDER funds through COMPETE 2020 and by Portuguese funds through FCT, under POCI-01-0145-FEDER-029803 (02/SAICT/2017) and POCI-01-0145-FEDER-006961 (UID/EEA/50014/2019).

Conflicts of Interest: The authors declare no conflict of interest.

\section{Nomenclature}

$\begin{array}{ll}\text { Indices } & \\ n & 0,-1,1 \\ j & 1,2,5,7 \\ k & \mathrm{a}, \mathrm{b}, \mathrm{c}\end{array}$

\section{Abbreviations}

MMC Modular multilevel converter

SLPWM Shift level pulse width modulation

HVDC High-voltage direct current

SMs Submodules

KVL Kirchhoff's Voltage Law

Variables

$i_{k}$

$I_{(u, l) k}$

$i_{\text {cirk }}$

$i_{d c}$

$v_{d c}$

$v_{(u, l) k}$

$v_{k}$

$I_{m j}$

$v_{m j}$

$I_{d c \_c i r}$

$I_{\text {mcirj }}$

$\beta_{j}$

$\alpha_{\text {cirj }}$

Output MMC currents

Upper and lower arm currents of the MMC

Circulating currents of the MMC

MMC dc-link current

MMC dc-link voltage

Parameters

L

Submodule voltages of the MMC

Output voltages of the MMC

Maximum magnitude of the $j$ th harmonic of the output current

Maximum magnitude of the $j$ th harmonic of the output voltage

dc component of the circulating current

Maximum magnitude of the $j$ th harmonic of the circulating current

Angle difference between the output current and voltage

Phase difference of the circulating current

Output inductance of the MMC

$R \quad$ Output resistance of the MMC

$L_{t} \quad$ Arm inductance of the MMC

$R_{t} \quad$ Arm resistance of the MMC

$\omega_{1} \quad$ Fundamental angular frequency of the MMC

$\omega_{j} \quad j$ th-order angular frequency of the MMC variables

$C_{(u, l) k} \quad$ Equivalent SM capacitors of the MMC arms 


\section{References}

1. Mehrasa, M.; Lesan, S.; Emeni, S.N.H.; Sheikholeslami, A. Passivity-based Control with Dual Lagrangian Model of Four-Wire Three-Level Three-Phase NPC Voltage-Source Rectifier. In Proceedings of the IEEE Conference Compatibility and Power Electronics, Badajoz, Spain, 20-22 May 2009; pp. 411-418.

2. Babaie, M.; Sharifzadeh, M.; Mehrasa, M.; Chouinard, G.; Al-Haddad, K. Supervised Learning Model Predictive Control Trained by ABC Algorithm for Common Mode Voltage Suppression in NPC Inverter. IEEE J. Emerg. Sel. Top. Power Electron. 2020. [CrossRef]

3. Babaie, M.; Sharifzadeh, M.; Mehrasa, M.; Baillargeon, L.; Al-Haddad, K. A Robust Fuzzy-Based Control Technique for Grid-Connected Operation of Sensor-Less PUC5 Inverter. In Proceedings of the 44th Annual Conference of the IEEE Industrial Electronics Society, Washington, DC, USA, 21-23 October 2018; pp. 5272-5276.

4. Cupertino, A.F.; Farias, J.V.M.; Pereira, H.A.; Seleme, S.I.; Teodorescu, R. Comparison of DSCC and SDBC Modular Multilevel Converters for STATCOM Application During Negative Sequence Compensation. IEEE Trans. Ind. Electron. 2019, 66, 2302-2312. [CrossRef]

5. Li, N.; Gao, F.; Hao, T.; Ma, Z.; Zhang, C. SOH Balancing Control Method for the MMC Battery Energy Storage System. IEEE Trans. Ind. Electron. 2018, 65, 6581-6591. [CrossRef]

6. Fan, B.; Li, Y.; Wang, K.; Zheng, Z.; Xu, L. Hierarchical System Design and Control of an MMC-Based Power-Electronic Transformer. IEEE Trans. Ind. Inform. 2017, 13, 238-247. [CrossRef]

7. Ferreira, V.D.N.; Cupertino, A.F.; Pereira, H.A.; Rocha, A.V.; Seleme, S.I.; Filho, B.D.J.C.; Cardoso, B. Design and Selection of High Reliability Converters for Mission Critical Industrial Applications: A Rolling Mill Case Study. IEEE Trans. Ind. Appl. 2018, 54, 4938-4947. [CrossRef]

8. Mehrasa, M.; Pouresmaeil, E.; Zabihi, S.; Catalão, J.P.S. Dynamic Model, Control and Stability Analysis of MMC in HVDC Transmission Systems. IEEE Trans. Power Deliv. 2017, 32, 1471-1482. [CrossRef]

9. Sharifzadeh, M.; Mehrasa, M.; Babaie, M.; Al-Haddad, K. Stable Frequency Response for Multi-Terminal MMC-HVDC System with DC Voltage Fluctuations. In Proceedings of the 45th Annual Conference of the IEEE Industrial Electronics Society (IECON), Lisbon, Portugal, 14-17 October 2019; pp. 3577-3582.

10. Mehrasa, M. Control of Modular Multilevel Converters in High Voltage Direct Current Power Systems. Ph.D. Thesis, University of Beira Interior, Covilha, Portugal, June 2019.

11. Alexander, A.; Thathan, M. Modelling and analysis of modular multilevel converter for solar photovoltaic applications to improve power quality. IET Renew. Power Gener. 2015, 9, 78-88. [CrossRef]

12. Shahnazian, F.; Adabi, J.; Pouresmaeil, E.; Mehrasa, M.; Catalão, J.P.S. Circulating Current Elimination of Grid-Connected Modular Multilevel Converters. In Proceedings of the IEEE International Conference on Environment and Electrical Engineering and 2018 IEEE Industrial and Commercial Power Systems Europe (EEEIC / I\&CPS Europe), Palermo, Italy, 12-15 June 2018; pp. 1-6.

13. Marzoughi, A.; Burgos, R.; Boroyevich, D.; Xue, Y. Design and Comparison of Cascaded H-Bridge, Modular Multilevel Converter, and 5-L Active Neutral Point Clamped Topologies for Motor Drive Applications. IEEE Trans. Ind. Appl. 2018, 54, 1404-1413. [CrossRef]

14. Ahmadijokani, M.; Mehrasa, M.; Sleiman, M.; Sharifzadeh, M.; Sheikholeslami, A.; Al-Haddad, K. A Back-Stepping Control Method for Modular Multilevel Converters. IEEE Trans. Ind. Electron. 2020. [CrossRef]

15. Mehrasa, M.; Pouresmaeil, E.; Zabihi, S.; Vechiu, I.; Catalao, J.P.S. A Multi-Loop Control Technique for the Stable Operation of Modular Multilevel Converters in HVDC Transmission Systems. Int. J. Electr. Power Energy Syst. 2018, 96, 194-207. [CrossRef]

16. Mehrasa, M.; Pouresmaeil, E.; Taheri, S.; Vechiu, I.; Catalao, J.P.S. Novel Control Strategy for Modular Multilevel Converters based on Differential Flatness Theory. IEEE J. Emerg. Sel. Top. Power Electron. 2017, 6, 888-897. [CrossRef]

17. Picas, R.; Ceballos, S.; Pou, J.; Zaragoza, J.; Konstantinou, G.; Agelidis, V.G. Closed-Loop Discontinuous Modulation Technique for Capacitor Voltage Ripples and Switching Losses Reduction in Modular Multilevel Converters. IEEE Trans. Power Electron. 2015, 30, 4714-4725. [CrossRef] 
18. Tu, Q.; Xu, Z.; Xu, L. Reduced Switching-Frequency Modulation and Circulating Current Suppression for Modular Multilevel Converters. IEEE Trans. Power Deliv. 2011, 26, 2009-2017.

19. Mo, R.; Li, H.; Shi, Y. A Phase-shifted Square Wave Modulation (PS-SWM) for Modular Multilevel Converter (MMC) and DC Transformer for Medium Voltage Applications. IEEE Trans. Power Electron. 2018, 34, 6004-6008. [CrossRef]

20. Kim, S.; Jeong, M.; Kim, J.; Lee, K. Hybrid Modulation Scheme for Switching Losses Reduction in a Modular Multilevel High-voltage Direct Current Converter. IEEE Trans. Power Electron. 2018, 34, 3178-3191. [CrossRef]

21. Deng, Y.; Wang, Y.; Teo, K.H.; Harley, R.G. A Simplified Space Vector Modulation Scheme for Multilevel Converters. IEEE Trans. Power Electron. 2016, 31, 1873-1886. [CrossRef]

22. Dekka, A.; Wu, B.; Zargari, N.R.; Fuentes, R.L. A Space-Vector PWM-Based Voltage-Balancing Approach with Reduced Current Sensors for Modular Multilevel Converter. IEEE Trans. Ind. Electron. 2016, 63, 2734-2745. [CrossRef]

23. Aleenejad, M.; Mahmoudi, H.; Jafarishiadeh, S.; Ahmadi, R. Fault-Tolerant Space Vector Modulation for Modular Multilevel Converters with Bypassed Faulty Submodules. IEEE Trans. Ind. Electron. 2019, 66, 2463-2473. [CrossRef]

24. Ronanki, D.; Williamson, S.S. A Simplified Space Vector Pulse Width Modulation Implementation in Modular Multilevel Converters for Electric Ship Propulsion Systems. IEEE Trans. Transp. Electrif. 2018, 5, 335-342. [CrossRef]

25. Deng, Y.; Wang, Y.; Teo, K.H.; Saeedifard, M.; Harley, R.G. Optimized Control of the Modular Multilevel Converter Based on Space Vector Modulation. IEEE Trans. Power Electron. 2018, 33, 5697-5711. [CrossRef]

26. Zhou, D.; Yang, S.; Tang, Y. Model Predictive Current Control of Modular Multilevel Converters with Phase-Shifted Pulse-Width Modulation. IEEE Trans. Ind. Electron. 2018, 66, 4368-4378. [CrossRef]

27. Edpuganti, A.; Rathore, A.K. Optimal Pulsewidth Modulation of Medium-Voltage Modular Multilevel Converter. IEEE Trans. Ind. Appl. 2016, 52, 3435-3442. [CrossRef]

28. McGrath, B.P.; Teixeira, C.A.; Holmes, D.G. Optimized Phase Disposition (PD) Modulation of a Modular Multilevel Converter. IEEE Trans. Ind. Appl. 2017, 53, 4624-4633. [CrossRef]

29. Mehrasa, M.; Sharifzadeh, M.; Sheikholeslami, A.; Pouresmaeil, E.; Catalao, J.P.S.; Al-Haddad, K. A Control Strategy based on the Upper and Lower's Arms Modulation Functions of MMC in HVDC Applications. In Proceedings of the IEEE International Conference on Industrial Technology (ICIT), Lyon, France, 20-22 February 2018; pp. 1873-1878.

30. Edpuganti, A.; Rathore, A.K. Optimal Pulsewidth Modulation for Common-Mode Voltage Elimination Scheme of Medium-Voltage Modular Multilevel Converter-Fed Open-End Stator Winding Induction Motor Drives. IEEE Trans. Ind. Electron. 2017, 64, 848-856. [CrossRef]

31. Mehrasa, M.; Pouresmaeil, E.; Akorede, M.F.; Zabihi, S.; Catalão, J.P.S. Function-based Modulation Control for Modular Multilevel Converters Under Varying Loading and Parameters Conditions. IET Gener. Transm. Distrib. 2017, 11, 3222-3230. [CrossRef]

32. Dekka, A.; Wu, B.; Zargari, N.R. A Novel Modulation Scheme and Voltage Balancing Algorithm for Modular Multilevel Converter. IEEE Trans. Ind. Appl. 2016, 52, 432-443. [CrossRef]

33. Mehrasa, M.; Pouresmaeil, E.; Zabihi, S.; Trujillo Caballero, J.C.; Catalão, J.P.S. A Novel Modulation Function-Based Control of Modular Multilevel Converters for High Voltage Direct Current Transmission Systems. Energies 2016, 9, 867. [CrossRef]

34. Tiezhu, W.; Lei, W.; Junxian, H.; Yifeng, D.; Yi, W.; Shanshan, W. Modified modulation strategy of MMC for wind farm integration. J. Eng. 2017, 2017, 1186-1190. [CrossRef]

35. Du, S.; Liu, J.; Liu, T. Modulation and Closed-Loop-Based DC Capacitor Voltage Control for MMC with Fundamental Switching Frequency. IEEE Trans. Power Electron. 2015, 30, 327-338. [CrossRef]

36. Mehrasa, M.; Hosseini, S.k.; Taheri, S.; Pouresmaeil, E.; Catalão, J.P.S. Dynamic performance control of modular multilevel converters in HVDC transmission systems. In Proceedings of the IEEE Electrical Power and Energy Conference (EPEC), Ottawa, ON, Canada, 12-14 October 2016; pp. 1-6. 
37. Pouresmaeil, E.; Mehrasa, M.; Shokridehaki, M.A.; Rodrigues, E.M.G.; Catalão, J.P.S. Control of modular multilevel converters for integration of distributed generation sources into the power grid. In Proceedings of the IEEE International Conference on Smart Energy Grid Engineering (SEGE), Oshawa, ON, Canada, 17-19 August 2015; pp. 1-6.

38. Pouresmaeil, E.; Mehrasa, M.; Rodrigues, E.; Godina, R.; Catalão, J.P.S. Control of Modular Multilevel Converters Under Loading Variations in Distributed Generation Applications. In Proceedings of the 2018 IEEE International Conference on Environment and Electrical Engineering and 2018 IEEE Industrial and Commercial Power Systems Europe (EEEIC/I\&CPS Europe), Palermo, Italy, 12-15 June 2018; pp. 1-6.

(C) 2020 by the authors. Licensee MDPI, Basel, Switzerland. This article is an open access article distributed under the terms and conditions of the Creative Commons Attribution (CC BY) license (http://creativecommons.org/licenses/by/4.0/). 